This item was submitted to Loughborough's Research Repository by the author.

Items in Figshare are protected by copyright, with all rights reserved, unless otherwise indicated.

\title{
Effect of layer thickness and cross-section geometry on the tensile and compression properties of 3D printed ABS
}

PLEASE CITE THE PUBLISHED VERSION

https://doi.org/10.1016/j.mtcomm.2019.100626

\section{PUBLISHER}

Elsevier BV

\section{VERSION}

AM (Accepted Manuscript)

\section{PUBLISHER STATEMENT}

This paper was accepted for publication in the journal Materials Today Communications and the definitive published version is available at https://doi.org/10.1016/j.mtcomm.2019.100626.

\section{LICENCE}

CC BY-NC-ND 4.0

\section{REPOSITORY RECORD}

Nomani, Junior, Daniel Wilson, Mariana Paulino, and Mazher Mohammed. 2019. "Effect of Layer Thickness and Cross-section Geometry on the Tensile and Compression Properties of 3D Printed ABS". Loughborough University. https://hdl.handle.net/2134/12625484.v1. 


\title{
Effect of layer thickness and cross-section geometry on the tensile and compression properties of 3D printed ABS
}

\author{
Junior Nomani ${ }^{1}$, Daniel Wilson ${ }^{2}$, Mariana Paulino ${ }^{2}$, Mazher Iqbal Mohammed ${ }^{2,3,4 *}$ \\ ${ }^{1}$ Faculty Office of Design and Creative Technologies, Mechanical Engineering Department, AUT \\ University, Auckland, New Zealand \\ ${ }^{2}$ School of Engineering, Deakin University, Waurn Ponds, Australia \\ ${ }^{3}$ School of Medicine, Deakin University, Waurn Ponds, Australia \\ ${ }^{4}$ Loughborough Design School, Loughborough University, Loughborough, UK
}

*Corresponding author: iqy2004@ hotmail.com

\begin{abstract}
This study examines the influence of deposition layer thickness on the mechanical properties of printed ABS material when manufacturing using Fused Filament Fabrication (FFF). Tensile and compression testing was performed to ASTM standards on samples printed with layer thickness between $0.2 \mathrm{~mm}$ and $0.8 \mathrm{~mm}$. Results found material strength and stiffness was greatest using smaller layer thicknesses, compared with larger layer thicknesses e.g. $\sigma_{y(0.2 \mathrm{~mm})}=31.5 \mathrm{MPa}, \quad U T S_{(0.2 \mathrm{~mm})}=38.2 \mathrm{MPa}$, compared with $\sigma_{y(0.8 \mathrm{~mm})}=23.0$ $\mathrm{MPa}, \operatorname{UTS}_{(0.8 \mathrm{~mm})}=31.0 \mathrm{MPa}$. The recorded changes in mechanical properties are explained by mechanisms relating to manufacturing residual porosity, the number of deposited layers promoting interlayer bonding strength, and the extrusion process resulting in material shear hardening. Findings have implications on the ability to reduce the overall part print time using a method of increased material deposition, and may have profound implications on comparative part integrity when utilising large volume deposition printing formats with unmodified ABS polymer. The findings from this study also highlight the need for current mechanical testing standards to accommodate appropriate guidelines for the testing of 3D printed material, given the wide variance of measured tensile and compression properties based on layer thickness and printed geometry.
\end{abstract}


Key words: layer thickness, layer height, FFF, interlayer bond strength, polymer hardening

\subsection{Introduction}

Additive Manufacturing (AM) has received growing interest for both research and industry-based applications, owning to the ability to realise parts and products with high degrees of complexity in configurations which were otherwise not possible. As such, AM has found wide utility in manufacturing applications with high degrees of complexity such as reproduction of the human form for medical applications $[1,2]$, or realisation of complex mathematically derived surfaces and lattice structures $[3,4]$. There are currently many different AM technologies commercially available with metal technologies dominating what is used industrially [5, 6]. However, the wider prevalence of metal AM technologies has been prohibitive owing to the high associated expense of such technologies, from the initial outlay of the device, its maintenance and consumable costs. By contrast, manufacturing of products by Fused Filament Fabrication (FFF) has increased considerably in the last decade, in part owing to the expiry of the original patents by Stratasys [7], alongside the adoption by the maker and open source communities [8]. Combined, such factors have made the technology more affordable, to a point where such devices are now accessible for home use.

Traditionally, FFF printed parts predominantly comprise polymers, but more recently there is growing interest in the use for manufacturing of composite materials, either blending different polymers [9], organic substances [10, 11], fibres [12] or metallic powders [11]. Arguably the low-cost nature, accessibility, and flexibility of the FFF platform, combined with the emerging performance materials, are now realising the potential of this technology to create functional parts and components from small to large objects and with varying degrees of mechanical strengths. Some of the most prolific uses of FFF technologies are for what could be called passive applications where high degrees of mechanical strength is not required, such as medical models $[13,14]$ and custom device components on 3D printers $[8,15]$,

However, FFF products have shown great resilience and can be applied to applications where higher degrees of mechanical stability are required. One such example is in uses as die 2 
tools fixtures and jigs in assembly-line manufacturing [16]. Grémare et. al, [17] used FFF printing to develop press die tools for sheet metal low-alloy steel sheets. FFF has even been applied in printing of large-scale products using industrial scaled systems, such as the Big Area Additive Manufacturing (BAAM). The BAAM system was developed to print large full-scale products such as molds for large industrial wind turbines, full-scale housing structures and even an entire car chassis [18]. With the increase of functional printed products comes the need for material characterisation of printed material and understanding how process parameters such as layer thickness selection influences the bulk material properties. Therefore, despite the affordability of the technology and its proven ability to manufacture highly complex structures, challenges still remain in terms of the wider commercial acceptance of FFF for commercial applications.

There are several gaps in the present literature on how the selection of layer thickness or layer height influences the mechanical properties of FFF printed materials. Sood et. al, [19] conducted a study measuring the tensile behaviour, flexural strength, and impact toughness of ABS (acrylonitrile butadiene styrene) material printed at layer thicknesses between 0.127 $0.254 \mathrm{~mm}$. The study found all three mechanical properties were higher when printed at the larger layer thickness of $0.254 \mathrm{~mm}$. The authors suggested the loss in strength when printing with smaller layer thickness was caused by weak interlayer bond strength and distortion due to on-set of high temperature gradients under print conditions. The authors published similar results in a later study [20] finding ABS material printed at $0.254 \mathrm{~mm}$ layer thickness attained greater compression strength compared to $0.178 \mathrm{~mm}$ and $0.127 \mathrm{~mm}$ layer thickness.

/ X å DetQ \&l.Q211] observed a different trend finding smaller layer thickness prints produced on this occasion in Polylactic Acid (PLA), resulting in higher flexural strength when performing 3-Point bending tests. The study reported PLA material printed at $0.1 \mathrm{~mm}$ layer thickness withstood three times more flexural loading than PLA printed at $0.3 \mathrm{~mm}$ layer

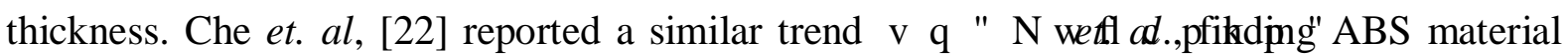
printed at $0.254 \mathrm{~mm}$ layer thickness retained higher tensile strength than printed samples at $0.330 \mathrm{~mm}$ layer thickness. Curiously, these trends are the opposite to those described by Sood et al. Additionally, none of the studies provided any underlying mechanism to the trend, making 
it more difficult to establish which study is a correct reflection of the build process, and further confounding the standardisation issue of FFF 3D printing. In a more recent study, Tymrak et. $a l$, [23] reported findings of PLA and ABS printed at $0.2 \mathrm{~mm}$ layer thickness resulted in higher tensile strength material compared to $0.3 \mathrm{~mm}$ and $0.4 \mathrm{~mm}$ layer thickness. This finding

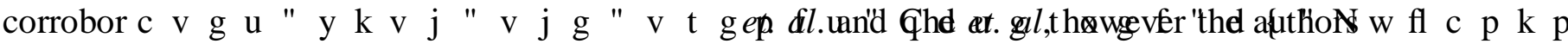
commented on it being unclear whether differences in mechanical properties were due to different layer thickness, print orientation or other factors.

A parametric study by $\mathrm{Wu}$ et. al, [24] found the optimal layer thickness to maximise part strength may actually lay between a minimum and maximum value. Wu et. al, reported higher mechanical strength in tension, compression and flexural loading was retained in ABS material printed at $0.3 \mathrm{~mm}$ layer thickness, compared to $0.2 \mathrm{~mm}$ and with a layer thickness of $0.4 \mathrm{~mm}$ retaining the lowest. Mohamed et. al, [25] shared similar results, finding the flexural modulus was higher in PC/ABS material printed at $0.254 \mathrm{~mm}$, in between material printed at $0.1778 \mathrm{~mm}$ and $0.3302 \mathrm{~mm}$ layer thickness.

Contrasting results from previous studies highlights that at present it is unclear whether a smaller or larger layer thickness would result in printed materials with greater mechanical properties and what the underlying mechanism for this would be from a material and manufacturing perspective. When considering layer thickness evaluation in FFF, the printer nozzle dictates the range over which a respective layer thicknesses can be manufactures, with the largest layer thickness generally being approximately the diameter of the nozzle. Therefore, observing a natural correlation is also difficult given the availability of standard printing nozzle sizes, creating a narrow layer thickness parameter range. In all present studies groups have used a standard $0.4 \mathrm{~mm}$ printer nozzle, limiting the maximum layer height to approximately $0.4 \mathrm{~mm}$. Despite all this uncertainty, / X å DeRQdL. [21] substantiated the importance of layer thickness through statistical analysis, finding it the major contributing parameter to flexural strength compared to deposition angle and percentage infill. It is imperative to both address this issue and determine the underlying mechanism to adequately predict mechanical performance if FFF printing is to be a viable mainstream manufacturing process. 
The aim of this study is to observe the effect of printing at different layer thickness on the mechanical properties related to strength in tension and compression loading and determine the physical factors to predict the mechanical performance. To add further novelty to the study, testing makes use of a $1 \mathrm{~mm}$ diameter nozzle for 3D printing, which allows for a greater range of layer thicknesses to be examined, which have yet to be reported in the literature. We focus our study on the use of ABS polymer and examine layer thickness of $0.2,0.4,0.6$ and $0.8 \mathrm{~mm}$. We then detail an experimental strategy to uncover the underlying mechanisms which result in measurable changes in mechanical strength. A final motivation for the study was to address the question of whether mechanical changes are occurring when printing with increased layer thicknesses. The practical implication of this are that the total print time is reduced for increased layer thickness, due to the ability to deposit a greater mass of material for a given set of printing parameters. As the relatively long manufacturing times are considered a limitation of AM, the study will attempt to provide insight to whether this limit can be address by increasing the material deposition rate with FFF.

\subsection{Experimental Methods}

Tensile and compression test coupons were printed on a commercial FFF printer (Lulzbot Mini, Aleph Objects Inc, USA) using a fixed parameter set shown in Table 1. Tensile samples were printed with the largest area flat upon the print bed and compression samples with the circular area flat upon the print bed, as shown in Fig. 1. 3D printing was performed with deposition layers alternating between raster angles of $45^{\circ}$ and $135^{\circ}$. All samples were manufactured using 2.85mm ABS filament material (Bilby3D, Australia) using 100\% infill. The intrinsic material properties, as specified by the P D Q X I D F WX U H U I s\$eet V X S S O I comprised $\mathrm{a}<\mathrm{R}$ X QnofuMis $=1.75 \mathrm{GPa}$ and an Ultimate Tensile Strength (UTS) $=40 \mathrm{MPa}$. Samples were printed at four independant layer thicknesses comprising 0.2, 0.4, 0.6 and $0.8 \mathrm{~mm}$ using a single printer nozzle with a diameter of $1 \mathrm{~mm}$. The nozzle was selected as the physical limits of a standard $0.4 / 0.5 \mathrm{~mm}$ nozzle would not allow for the printing of larger thicknesses examined in this study however, would mean the strand thickness seen in the $\mathrm{x}-\mathrm{y}$ layer direction would be of a $1 \mathrm{~mm}$ thickness.

5 
a)

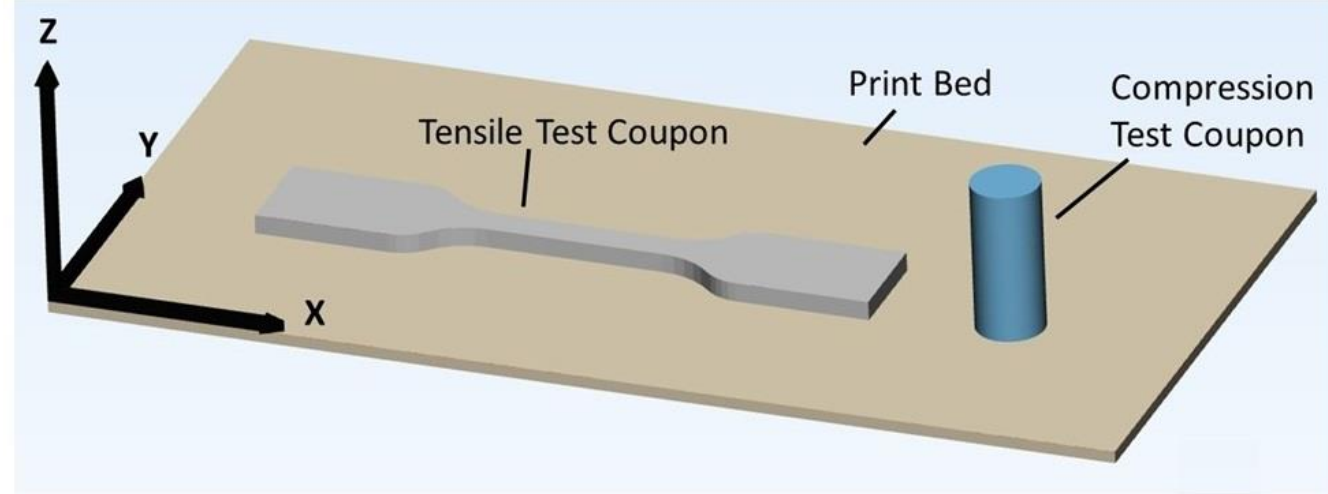

b) i)

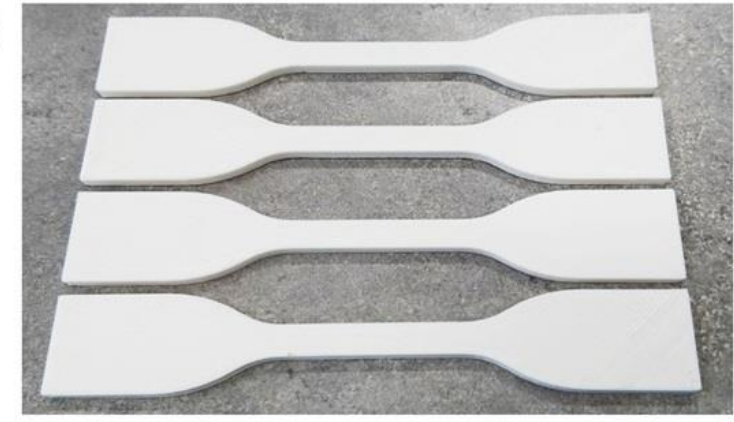

ii)

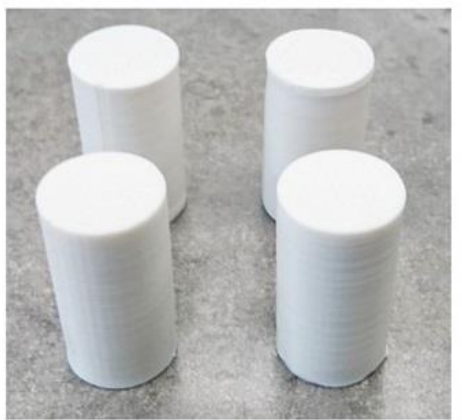

Figure. 1: a) Schematic setup of sample printed orientation and b) ABS printed mechanical testing samples for (a) Tensile and (b) Compression.

Flat type IV specimens were prepared for tensile samples according to ASTM \pm D63815 [26]. This consisted of a gauge cross-section $6 \mathrm{~mm} \times 3 \mathrm{~mm}(\mathrm{bxh})$ and $7.62 \mathrm{~mm}$ gage length. Compression samples were prepared according to ASTM-D695 [27], using a cylindrical geometry of $12.7 \mathrm{~mm}$ diameter and $25.4 \mathrm{~mm}$ height. A minimum of 5 samples were examined for each single layer thickness in following with standard ASTM test procedures. Figure 1b) shows images of the 3D printed tensile and compression samples and Table 2 shows the measured gage area of printed samples. All tests were conducted using a universal mechanical testing machine (INSTRON 5969, USA) with a 50kN load frame. All specimens were tested using a strain rate of $1 \mathrm{~mm} / \mathrm{min}$ until failure, which was determined by fracture. For compression tests, failure criterion was determined by crack propagation becoming visible on the surface or when the test machine became stationery, i.e. was no longer moving at the intended strain rate. 
Table 1: Printer specifications and fixed parameters

\begin{tabular}{cc}
\hline Fixed printing conditions & Description \\
\hline Printer Model / Type & Lulzbot Mini \\
Printer build size & $150 \mathrm{~mm} \times 150 \mathrm{~mm} \times 150 \mathrm{~mm}$ \\
Base material & $\mathrm{ABS}$ \\
Support material & $\mathrm{ABS}$ \\
Nozzle temperature & $235^{\circ} \mathrm{C}$ \\
Bed temperature & $105^{\circ} \mathrm{C}$ \\
Print Speed & $60 \mathrm{~mm} / \mathrm{s}$ \\
Raster angle/s & $45^{\circ}$ and $135^{\circ}$ \\
Print Orientation & $0^{\circ}($ flat on bed $)$ \\
Number of shells & 2 \\
Infill $\%$ & $100 \%$ \\
\hline
\end{tabular}

Table 2: Measured gage region for tensile and compression samples for printed layer

\begin{tabular}{|c|c|c|c|c|}
\hline Layer thickness & $0.2 \mathrm{~mm}$ & $0.4 \mathrm{~mm}$ & $0.6 \mathrm{~mm}$ & $0.8 \mathrm{~mm}$ \\
\hline & \multicolumn{4}{|c|}{ Tensile samples \pm ASTM D638 (Type IV) } \\
\hline Base (mm) & 3.47 & 3.56 & 3.88 & 3.76 \\
\hline Height (mm) & 6.20 & 6.02 & 6.02 & 6.27 \\
\hline \multirow[t]{2}{*}{$\begin{array}{l}\text { Printing time of single } \\
\text { sample ( } \mathrm{min})\end{array}$} & 13 & 8 & 6 & 6 \\
\hline & \multicolumn{4}{|c|}{ Compression samples \pm ASTM D695 } \\
\hline$\varnothing$ Diameter (mm) & 12.87 & 12.89 & 12.95 & 12.70 \\
\hline Height (mm) & 25.48 & 25.66 & 25.60 & 25.89 \\
\hline $\begin{array}{l}\text { Printing time of single } \\
\text { sample }(\mathrm{min})\end{array}$ & 20 & 11 & 8 & 6 \\
\hline
\end{tabular}




\subsection{Results}

Table 3 and 4 display a summary of tensile and compression test results. Examining both the tensile and compression data we see a reduction in strength and stiffness with increasing layer thickness. The $0.2 \mathrm{~mm}$ layer thickness material measured the highest yield and elastic modulus in tension and compression, including a $U T S_{0.2 \mathrm{~mm}}=38.5 \mathrm{MPa}$, which is in close agreement with the manufacturers stated value of $U T S_{\mathrm{ABS}}=40 \mathrm{MPa}$. While $0.4 \mathrm{~mm}$ and $0.6 \mathrm{~mm}$ layer thickness samples matched similar $<$ R X Qnho\$ukis, Yield Strength and UTS, the $0.8 \mathrm{~mm}$ layer thickness sample displayed the lowest strength and modulus in tension and compression. The widest ranges included tensile yield $\Delta \sigma_{y(0.2 \mathrm{~mm}-0.8 \mathrm{~mm})}=27 \%$, and compression modulus $\Delta E_{(0.2 m m-0.8 m m)}=37 \%$.

Table 3: Tensile results summary (averages, $n=5$ )

\begin{tabular}{cccccc}
\hline $\begin{array}{c}\text { Layer } \\
\text { Thickness } \\
(\mathrm{mm})\end{array}$ & $\begin{array}{c}<\text { R X Q J Yield Strength } \\
\text { Modulus } \\
(\mathrm{GPa})\end{array}$ & $\begin{array}{c}\text { Ultimate Tensile } \\
(\mathrm{MPa})\end{array}$ & $\begin{array}{c}\text { Uniform } \\
\text { Strength } \\
(\mathrm{MPa})\end{array}$ & $\begin{array}{c}\text { Total } \\
\text { Elongation }\end{array}$ & $\begin{array}{c}\text { Elongation } \\
(\%)\end{array}$ \\
\hline $0.2 \mathrm{~mm}$ & 2.00 & 31.5 & 38.2 & $2.46 \%$ & $3.88 \%$ \\
$0.4 \mathrm{~mm}$ & 1.72 & 26.5 & 36.5 & $2.53 \%$ & $4.48 \%$ \\
$0.6 \mathrm{~mm}$ & 1.77 & 25.0 & 34.5 & $2.42 \%$ & $3.00 \%$ \\
$0.8 \mathrm{~mm}$ & 1.55 & 23.0 & 31.0 & $2.42 \%$ & $4.29 \%$ \\
\hline$\Delta_{(0.2 \mathrm{~mm}-0.8 \mathrm{~mm})} \%$ & $23 \%$ & $27 \%$ & $19 \%$ & $1 \%$ & $-10 \%$ \\
\hline
\end{tabular}


Table 4: Compression results summary (averages, $n=5$ )

\begin{tabular}{ccc}
\hline $\begin{array}{c}\text { Layer Thickness } \\
(\mathrm{mm})\end{array}$ & $\begin{array}{c}\text { Compression } \\
\text { Modulus }(\mathrm{GPa})\end{array}$ & $\begin{array}{c}\text { Compression Yield } \\
(0.1 \%)(\mathrm{MPa})\end{array}$ \\
\hline $0.2 \mathrm{~mm}$ & 1.32 & 32.1 \\
$0.4 \mathrm{~mm}$ & 1.22 & 25.5 \\
$0.6 \mathrm{~mm}$ & 1.04 & 28.0 \\
$0.8 \mathrm{~mm}$ & 0.83 & 26.0 \\
\hline$\Delta(0.2 \mathrm{~mm}-0.8 \mathrm{~mm}) \%$ & $37 \%$ & $19 \%$ \\
\hline
\end{tabular}

\subsection{Tensile Strength}

Tensile curves illustrated in Fig. 2a) show a clear distinction in strength between the printed samples of different layer thickness, with an approximate $25 \%$ reduction in tensile strength between $0.2 \mathrm{~mm}$ and $0.8 \mathrm{~mm}$. The trend shows that as material layer thickness becomes smaller the test coupon strength increases. Tensile testing for a respective layer thickness displayed repeatable behaviour in both the elastic and plastic region up to maximum loading

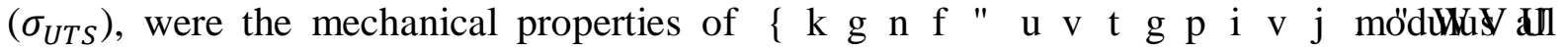
displayed low variance. Max variance was found in Yield Strength and min variance in $<\mathrm{R}$ X Qho $\$$ uNas with properties comprising 1-5\% error range based on standard deviation, see Fig. 2b).

Uniform elongation exhibited a shared strain point between all layer thickness samples, as seen Fig. 2b). This implies a common limit that under the same strain rate, printed material will uniformly elongate to the same relative degree and hold its maximum loading capacity at a strain between $2.11 \%-2.56 \%$. There is no evidence of strain hardening beyond the UTS, as the tensile stress shows to gradually decline until fracture. 
a)

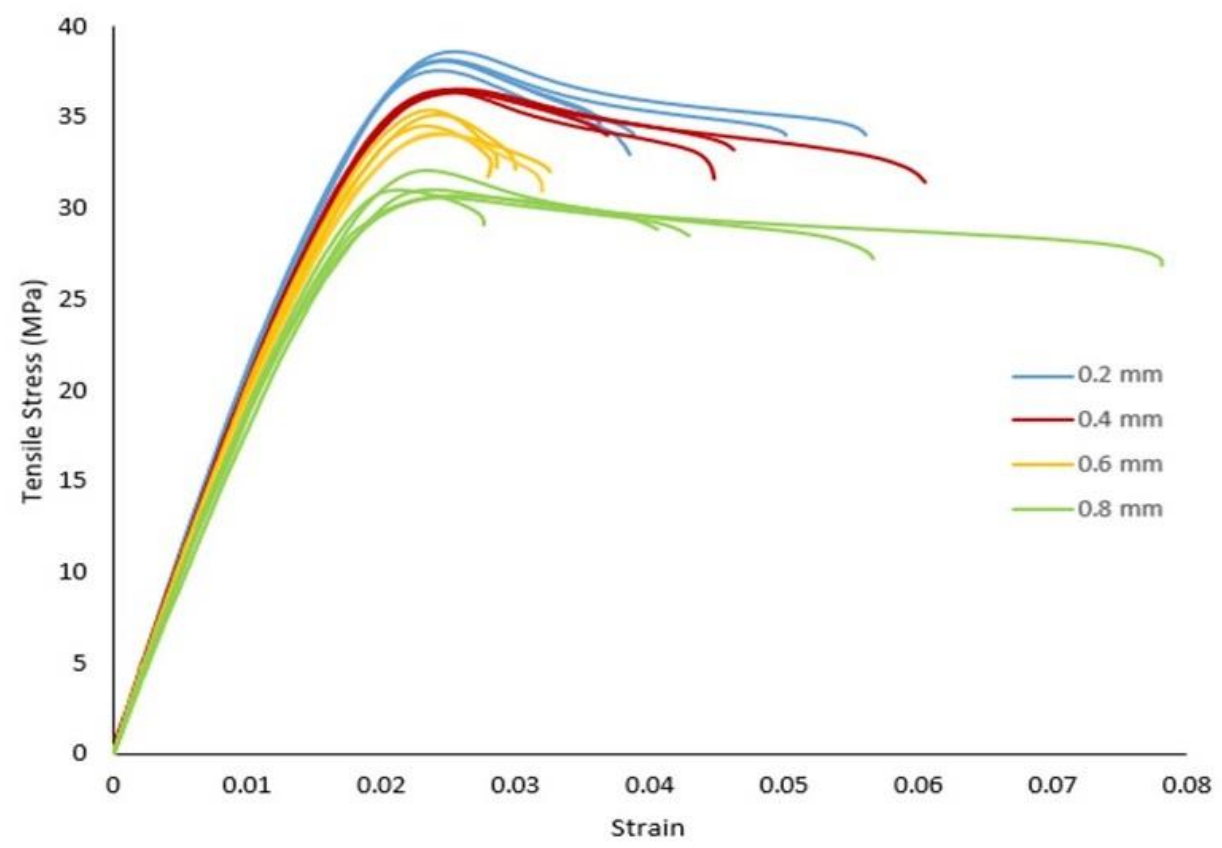

b)
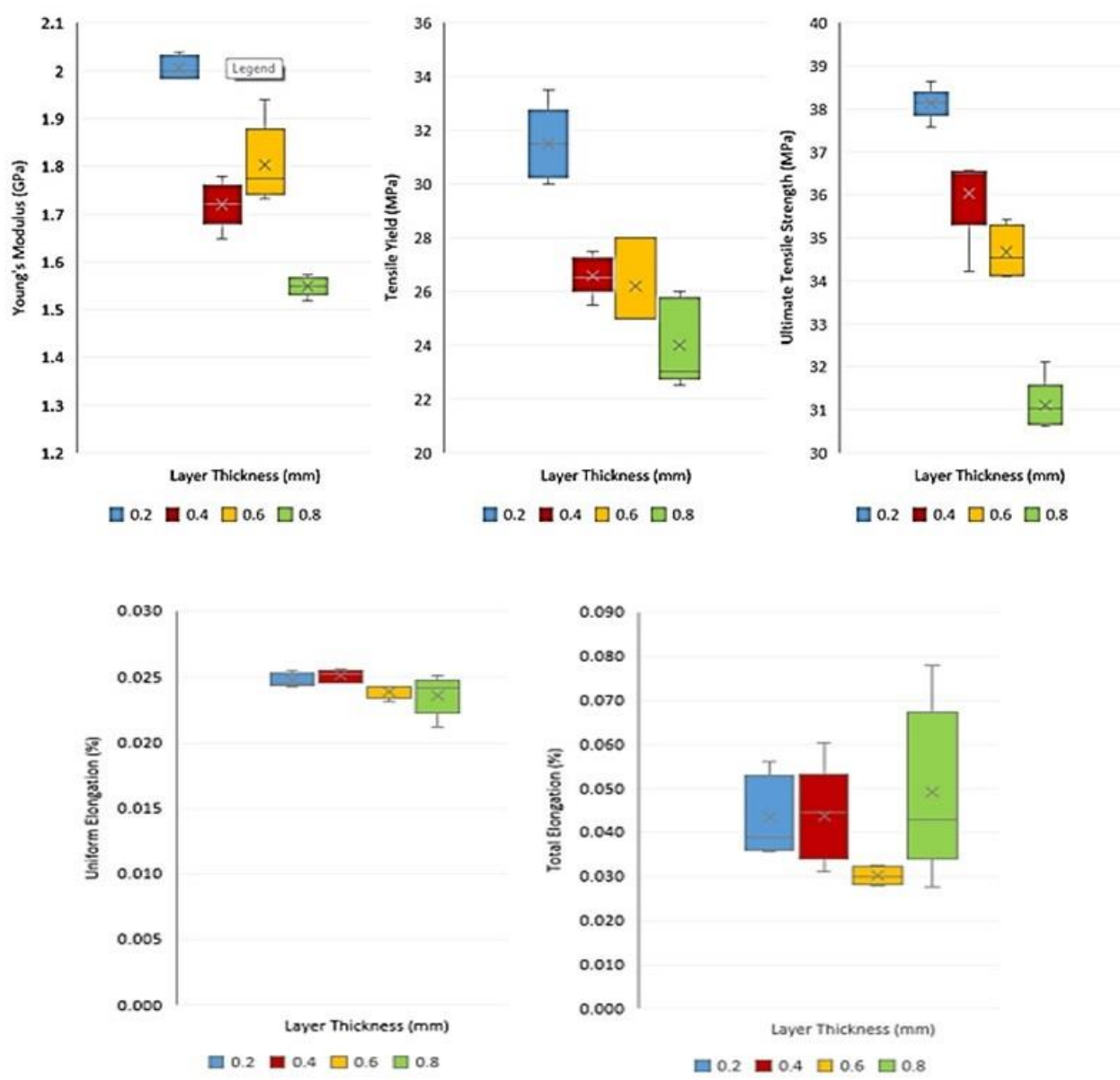
Figure 2: a) Tensile stress-strain curves on ABS printed at layer thickness between $0.2-0.8 \mathrm{~mm} . \mathrm{b}$ ) Box and whisker plot mechanical properties 0.2 to $0.8 \mathrm{~mm}$, (a) Young's Modulus, (b) Yield Strength, (c) Ultimate Tensile Strength (UTS), (d) Uniform Elongation and (e) Total Elongation.

The tensile behaviour in the plastic necking region was found to lack repeatability for each layer thickness examined, with the total elongation and strain at fracture, displaying large variances, as evident in Fig. 2. However, the $0.6 \mathrm{~mm}$ layer thickness samples showed consistent repeated fracture in the strain region $\varepsilon=0.030$. This occurrence could be tied to improved bond layering conformity when printing at $0.6 \mathrm{~mm}$ layer thickness for the current printer set up.

The nature of the fracture for the layered samples can be described as brittle given the low amount of plastic deformation. Fig. 3. displays microscope images of the cross-sectional area of the various fractured tensile samples. With respect to the fracture dynamics and plastic deformation, the two most influential factors would comprise the interlayer bond strength and the fraction of micro-porosity within the failure cross-section. Examining the failure planes in tested samples, it was found varying percentage porosities were observed, with larger individual pores observed on samples of $0.6 \mathrm{~mm}$ and $0.8 \mathrm{~mm}$ layer thickness, as seen in Fig. 3c) and d). The combination of weak interlayer bond strength and higher porosity would correlate to weaker material and quicker failure, as observed in the mechanical tests. The propagation of failure in brittle polymers is well associated with crazing and molecular void formation. The presence of porosity in a given test coupon would create an initiation point for crazing failure, and upon loading, triggers layer delamination. Ideally, rigorous process control during the printing process would reduce such porosity related defects, resulting in more predictable material behaviour under loading. However, such porosity is a known limitation to the FFF AM build process [28] and difficult to eliminate without material over extrusion, conversely resulting in either surface based defects or part printing failure. 

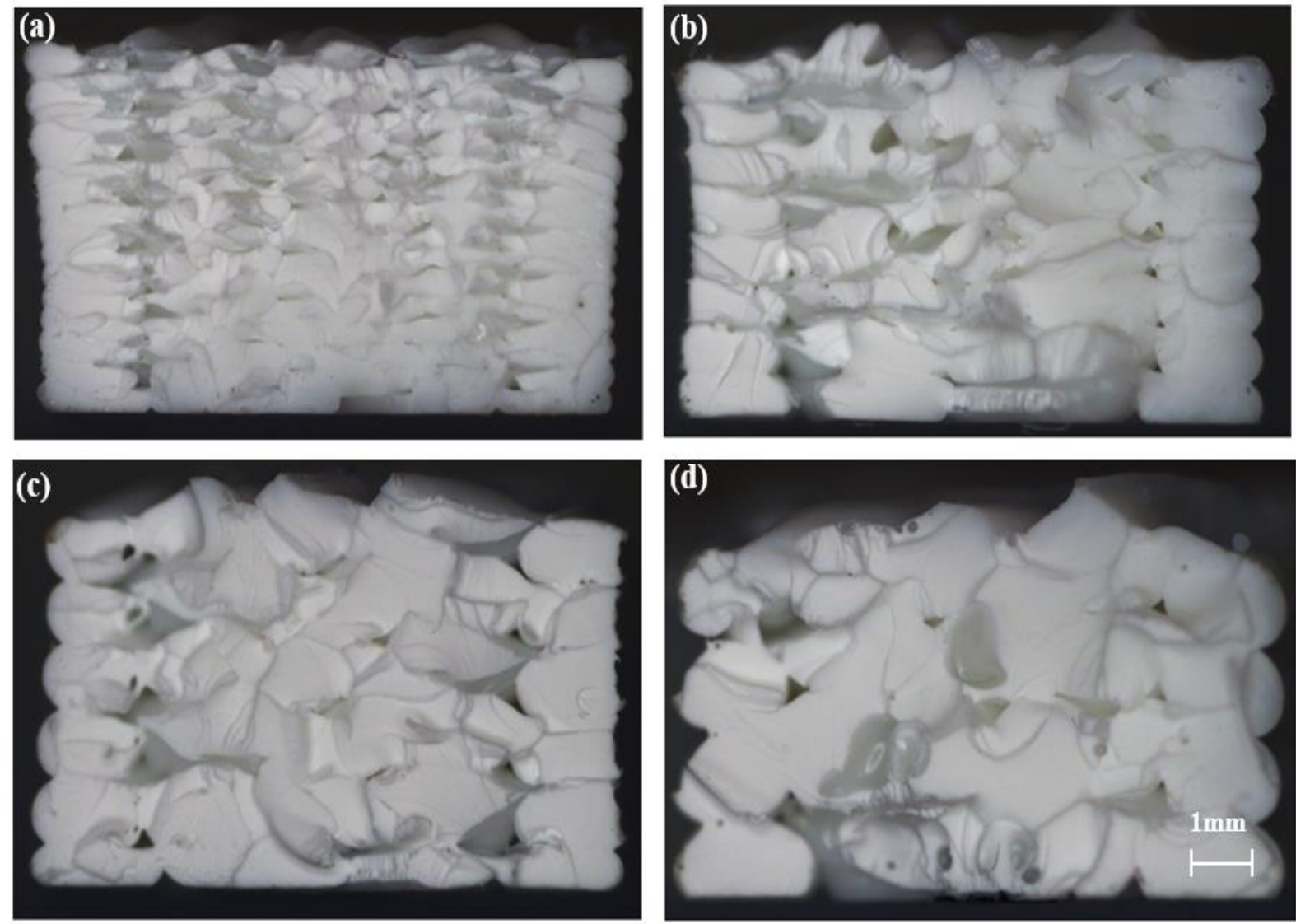

Figure 3: Optical images on cross-section of tensile samples on fracture area (a) $0.2 \mathrm{~mm}(\mathrm{~b}) 0.4 \mathrm{~mm}(\mathrm{c})$ $0.6 \mathrm{~mm}$ and (d) $0.8 \mathrm{~mm}$ layer thickness, $1 \mathrm{~mm}$ scale for all images

\subsection{Compression Strength}

When examining the compression tests data, a similar trend was found where the compression strength increased as the printing layer thickness decreases. The compression plot shown in Fig. 4a). shows ABS to be both stronger and stiffer at $0.2 \mathrm{~mm}$, when compared to $0.8 \mathrm{~mm}$ layer thickness. Both compression yield and modulus were highest in $0.2 \mathrm{~mm}$ layer thickness, which reduced with increasing layer thickness, as seen in Fig. 4b). 


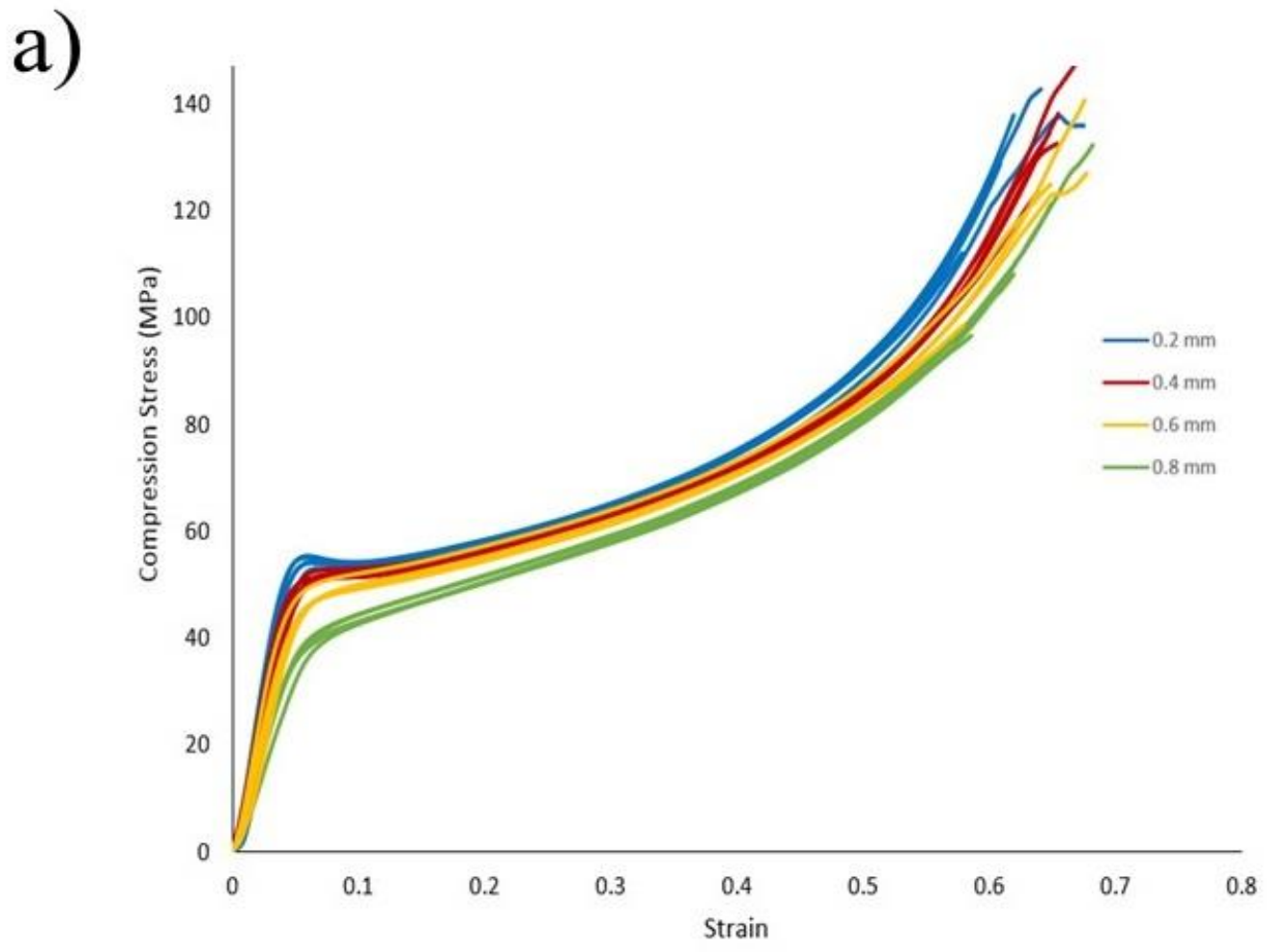

b)
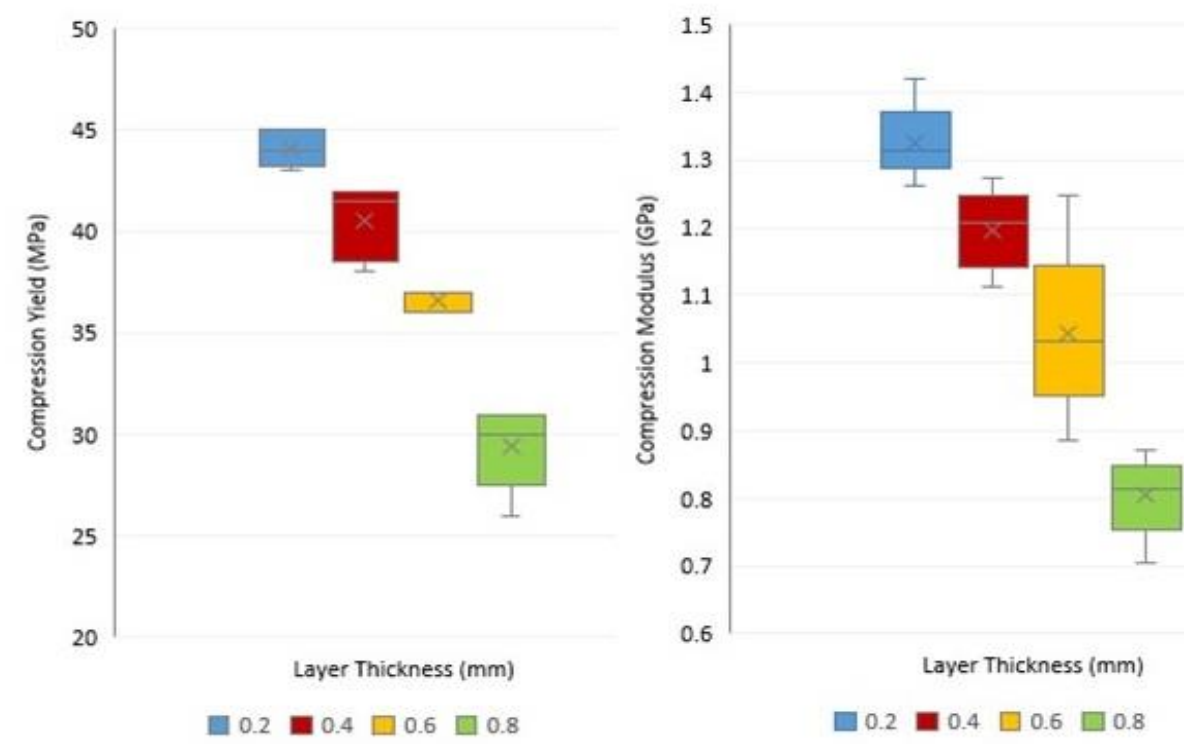

Figure 4: a) Compression stress-strain curves on ABS printed at layer thickness between 0.2 and 0.8 $m m$. b) Box and whisker plots of mechanical properties for layer thicknesses of 0.2 to $0.8 \mathrm{~mm}$ for Compressive Yield and Compressive Modulus 
Fig. 5. shows compression failure in a $0.2 \mathrm{~mm}$ layer thickness sample. During failure a crack initiates on the surface layer in the region of highest stress concentration and propagates along the surface until more fracture release energy is required. In 3D printed structures the surface crack initiates, before a new crack in the $1^{\text {st }}$ sub-layer which propagates to release further fracture energy, and the process repeats into the $2^{\text {nd }}$ sub-layer. The $2^{\text {nd }}$ sub-layer image in Fig. 5. shows evidence of necking occurring in the strands of the bulk layer, and are indicative of the layers are being pulled apart perpendicular to the applied load. Fractured surfaces also displayed evidence of delamination occurring during crack propagation.

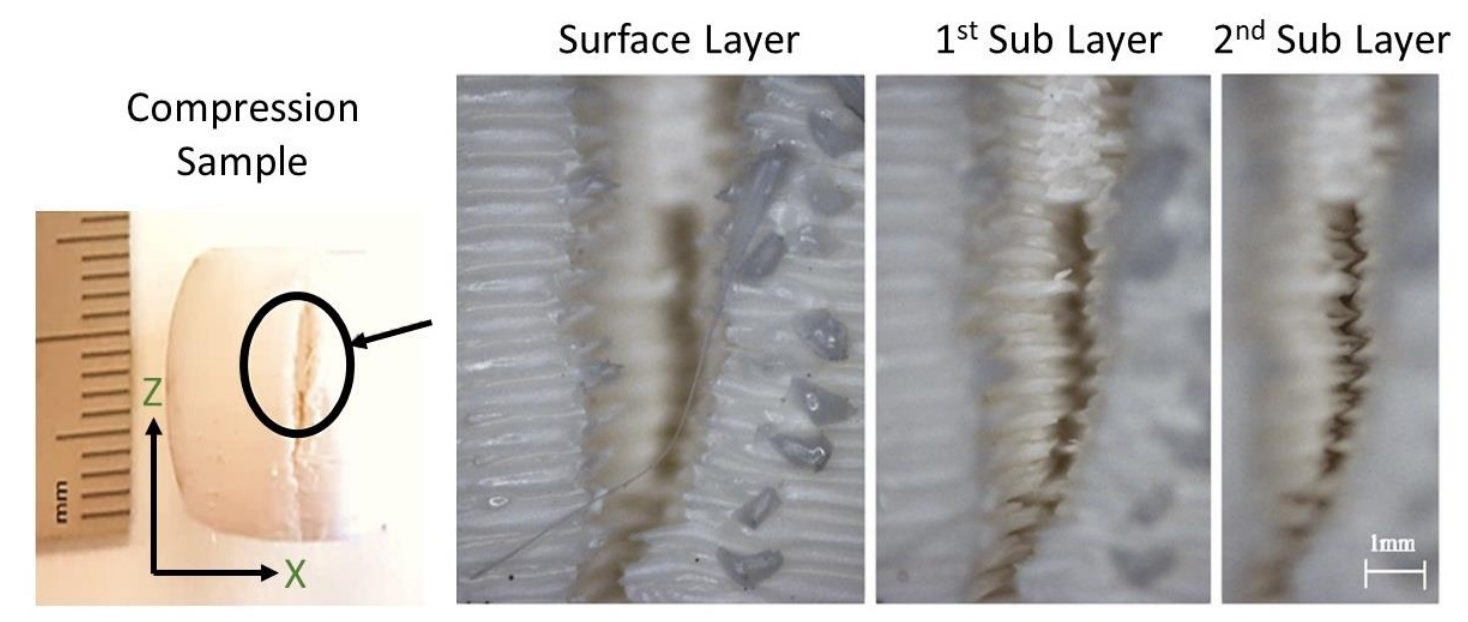

Figure 5: Fractured region on compression samples showing crack initiation and propagation on the outer surface and internal sub-surface layers, $1 \mathrm{~mm}$ scale for all images

4.0 Strength degradation mechanisms influenced by layer thickness

Tensile and compression results from the previous section, found mechanical strength and stiffness of printed ABS material to be widely influenced by the selection of layer thickness. Improved mechanical properties are acquired under smaller layer thickness prints which coincide with findings from previous studies [21-23, 29]. Previous studies had focused on the use of a standard $0.4 \mathrm{~mm}$ printer nozzle and so thicknesses beyond $0.4 \mathrm{~mm}$ were not examined. In the present study we have focused on examining effects at larger layer thickness 
regimes, and confirm that previously reported trends continue for larger layer thicknesses of 0.6 and $0.8 \mathrm{~mm}$. Part of our motivation to examine larger layer thicknesses in this study was to assess methods to overcome the time limitation when 3D printing using FFF. It can be seen in table 2 that for increased layer thickness the overall part printing time reduces due to more material being deposited over the same translational time of the printer head. Ultimately, we have discovered that the manufactured samples at 0.6 and $0.8 \mathrm{~mm}$ have a lower mechanical strength and stiffness compared to $0.4 \mathrm{~mm}$ and $0.2 \mathrm{~mm}$ layer thickness, despite reduction in print time. This finding opens up interesting possibilities for material design applications, where the desired mechanical strength for a printed component could be controlled by selection of layer thickness. However, it is critical to understand what underlying mechanisms are causing the change in bulk mechanical strength with printed layer thickness. A review of the current literature found a lack of agreement in proposed descriptions of what these mechanisms could be. We attempt to address this and identify three possible candidate factors, before evaluating their likelihood based on the present experimental and literature based evidence.

\subsection{Porosity related strength degradation}

Depositing material at larger layer thickness may lead to an increased difference between intended deposition volume and actual deposition volume. This can be caused by discrepancies in the actual deposited material relative to machine instructions from the slicing software or improper process parameters such as percentage deposition overlap, extrusion rate, print speed, etc. Therefore, tests were conducted to examine the cross section across the bulk of a printed part, for porosity at each layer thickness. Porous regions were visible in the crosssection area of fractured tensile samples, as shown previously in Fig. 3. However, given the elastic properties of plastics when under tension to display creep deformation, it was unclear if the observed porosity occurred due to the test conditions or was intrinsic manufacture related porosity. It is reasonable to assume that residual porosity in the bulk material would create regions of high-stress concentration under loading, triggering de-bonding and craze formation causing growth and sequential fracture. Therefore, the strength degradation observed with 
material printed at larger layer thickness could be explained with having greater presence of residual porosity.

a)
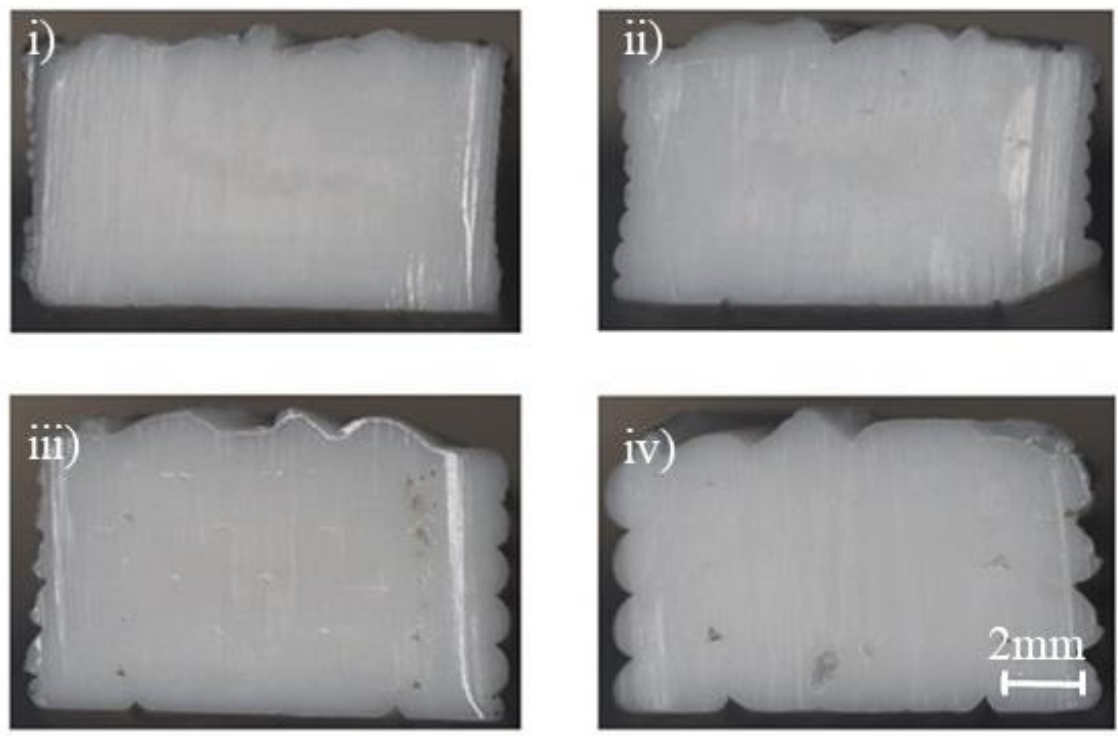

b)

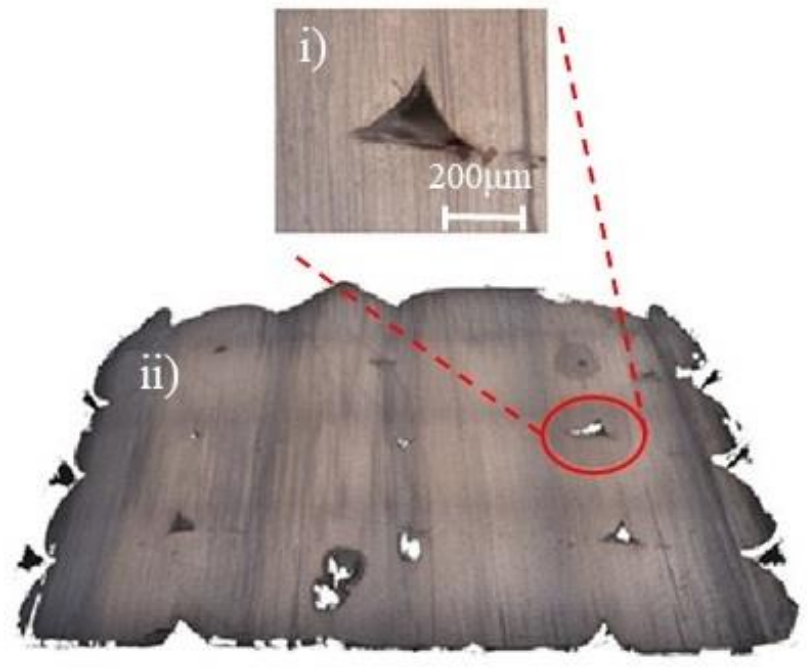

Figure 6: a) Porosity analysis on gage cross-section of non-tested ABS tensile samples printed at layer thickness (i) $0.2 \mathrm{~mm}$, (ii) $0.4 \mathrm{~mm}$, (iii) $0.6 \mathrm{~mm}$ and (iv) $0.8 \mathrm{~mm}$. b) Porosity analysis in bulk material on tensile samples using 3D scanning optical profilometer, depicting i) a magnification of one such porous region and ii) a 3D Optical topography scan of the section gauge area. 
Table 5 shows the measured mass and the calculated volume using density for ABS $\rho_{A B S}=1.05 \mathrm{~g} / \mathrm{cm}^{3}$ for the tensile specimens. Assuming the difference in volume and mass is explained by the degree of bulk porosity, then the max \% volume difference values in Table 5 show the $0.8 \mathrm{~mm}$ tensile samples contained $2.72 \%$ less volume and mass than $0.2 \mathrm{~mm}$ samples.

Table 5: Mass and Volume measurement of tensile samples

\begin{tabular}{cccc}
\hline $\begin{array}{c}\text { Layer thickness } \\
(\mathrm{mm})\end{array}$ & $\begin{array}{c}\text { Measured mass } \\
(\mathrm{g})\end{array}$ & $\begin{array}{c}\text { Calculated volume } \\
\left(\mathrm{cm}^{3}\right)\end{array}$ & $\begin{array}{c}\text { \% Vol difference } \\
\text { between } 0.2 \mathrm{~mm} \\
\text { sample }\end{array}$ \\
\hline $0.2 \mathrm{~mm}$ & 5.14 & 4.90 & $0 \%$ \\
$0.4 \mathrm{~mm}$ & 5.08 & 4.84 & $1.16 \%$ \\
$0.6 \mathrm{~mm}$ & 5.05 & 4.81 & $1.75 \%$ \\
$0.8 \mathrm{~mm}$ & 5.00 & 4.76 & $2.72 \%$ \\
\hline
\end{tabular}

To measure the amount of residual porosity residing in the bulk region, non-tested tensile samples were sectioned at the gage-cross section for further visual inspection, as seen in Fig. 6a). Sectioning was performed by wet-cutter grinding followed by cleaning in an ultrasonic cleaner using distilled water. The surface topography of the cross-section was then mapped using a surface profilometer (Infinite Focus, Alicona, Austria) to visualise and porosities within the bulk material, as can be seen in Fig. 6b). Using this approach, the percentage porosity could be accurately determined based on the ratio of void space to bulk material. This was repeated across all manufactured layer thicknesses and a porosity summary can be seen in Table 6 .

Table 6: Estimated porosity in gage cross-section on printed tensile samples

\begin{tabular}{cccc}
\hline Layer & Average Force & Estimated \% porosity based on & Measured Porosity \\
Thickness & at UTS (N) & measured force at UTS and & (\%) 3D mapped \\
$(\mathrm{mm})$ & & $\boldsymbol{\sigma}_{\boldsymbol{U T S}(\boldsymbol{A B S})}=40 \mathrm{MPa}$ & scanning \\
\hline
\end{tabular}




\begin{tabular}{llll}
\hline 0.2 & 820.00 & $-3.7 \%$ & $0.14 \%$ \\
0.4 & 779.75 & $1.9 \%$ & $0.19 \%$ \\
0.6 & 809.87 & $5.9 \%$ & $1.15 \%$ \\
0.8 & 733.16 & $13.9 \%$ & $2.74 \%$ \\
\hline
\end{tabular}

Based on an ideal UTS strength value for ABS, which assumes no residual porosity across the part cross section, we estimated the UTS based on the reduction in cross sectional area as a result of the voids, relative to a void free cross section. The estimated \% porosity was determined by the difference between the original measured area and calculated area $A$ using $\sigma=F / A$, where $\sigma=40 \mathrm{MPa}$ (ideal UTS strength for ABS) and $F$ is the measured force at UTS. In this approximation we assumed the tensile sample to perform with no anisotropic behaviour in the absence of voids, while neglecting the influence of the void spaces to create stress concentration regions that would alter the measured UTS. Table 6 shows the calculated estimate of the porosity and the actual measured porosity, where it can be seen there is a discrepancy in values across all layer thicknesses. It was found the detected porosity in the bulk cross-sections was not sufficient to explain the measured loss in mechanical strength with increasing layer thickness material. In particular, at a $0.8 \mathrm{~mm}$ layer thickness the measured percentage porosity was one fifth the required estimated percentage porosity. We therefore assume there must be some additional underlying factor which explain to the loss in mechanical performance.

4.2 Number of deposition layers increasing the bulk interlayer bond strength

When using AM, layer thickness determines the total number of deposition layers necessary to build a respective volume along both the vertical direction. Examining the mechanism of the build process closer, a layer is formed from the entanglement of individual polymer strands within the individually deposited polymer fibres, though a process of thermal diffusion [20]. Therefore, a bond is present between deposited fibres on a given layer, in addition to between layers. We can simplify this phenomena and consider the polymer entanglement only between individual build layers as the associated interlayer bond strength 18 
$\sigma_{\text {interlayer. }}$ If we assume the deposit layers are uniform, classical laminate theory can be applied to printed layers, as shown in Fig. 7a). Under axial loading, a shear stress is required to overcome the interlayer bond strength, initiating delamination and sequential failure. According to this model, the overall tensile strength $\sigma_{U T S}$ is the sum of the bulk material strength, $\sigma_{\text {Bulk }}$, and combined interlayer bond shear strength, $\tau_{\text {interlayer }}$, of $x$ layers, as shown in Eqn. 1. An analogous relationship to describe the overall stiffness is presented in Eqn. 2. Both equations propose the number of layers present in volume of printed material will influence properties such as UTS and elastic modulus due to the adhesion bond strength. When comparing the tensile and compression strength curves for the different printed layer thickness samples shown previously in Fig. 2. and Fig. 4, the 0.2mm layer thickness material displayed the highest Yield, UTS in tensile and elastic modulus. For this layer thickness a greater number of build layers are required to print this sample as compared to instances of larger layer thicknesses e.g. $0.4 \mathrm{~mm}$ to $0.8 \mathrm{~mm}$.

$$
\begin{aligned}
& \sigma_{U T S}=\sigma_{B u l k}+x \tau_{\text {interlayer }} \\
& E=E_{\text {Bulk }}+x G_{\text {interlayer }}
\end{aligned}
$$

Based on measured tensile data, Fig. 7b). shows a comparative plot of the various mechanical properties, considering the number of horizontal build layers existing in the gauge cross-section of the printed tensile samples. For an ASTM type IV tensile samples, the gauge cross section is $6 \mathrm{~mm} \times 3 \mathrm{~mm}$, this translates to 15 horizontal layers for $0.2 \mathrm{~mm}$ layer thickness, and 4 layers for $0.8 \mathrm{~mm}$ layer thickness print. 
a)

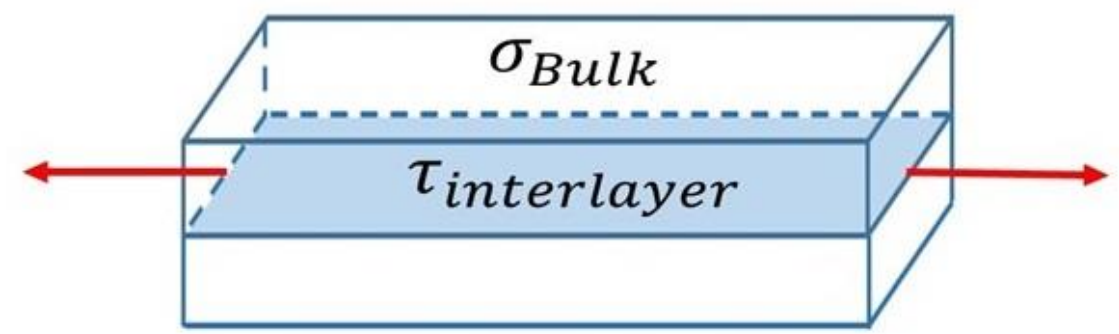

b)

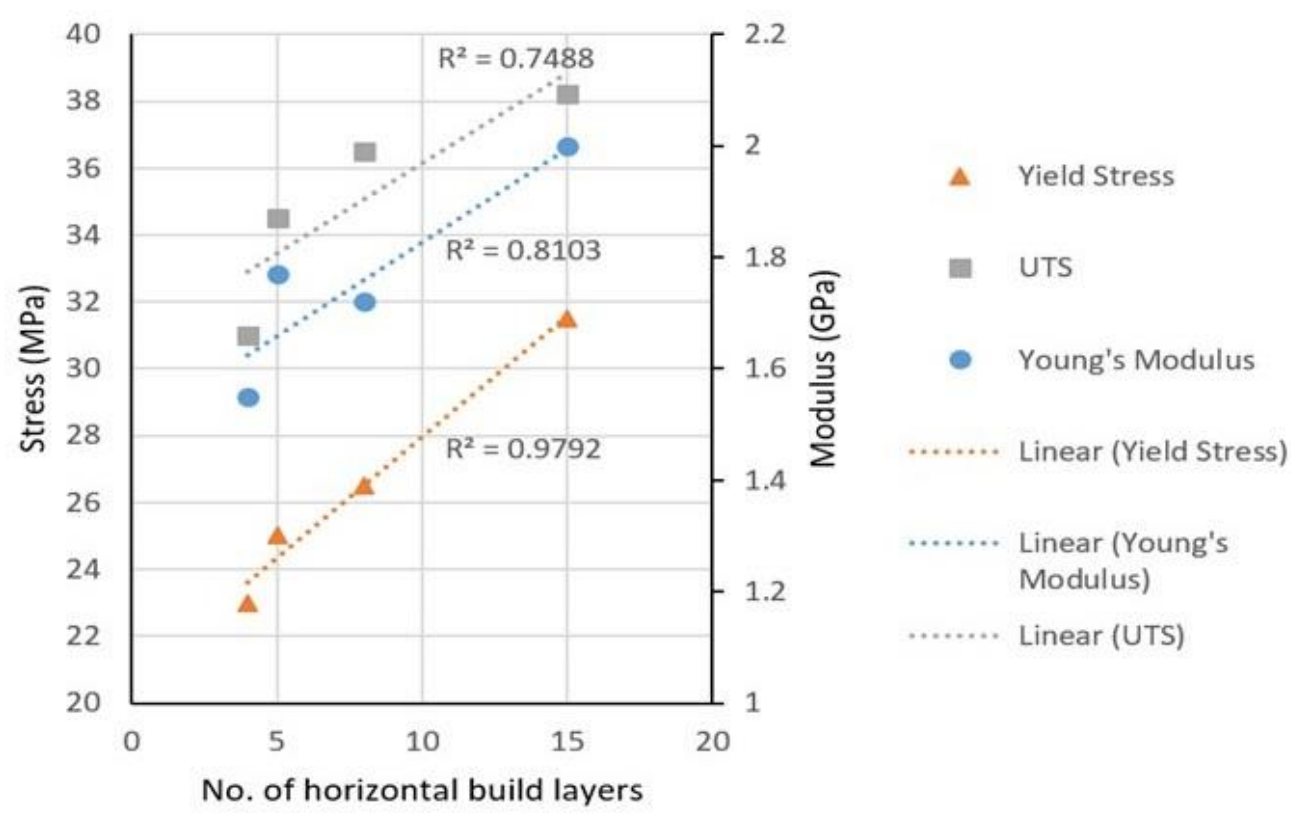

Figure 7: a) Schematic diagram of interlayer bond strength based on classical laminate theory. $b$ ) Mechanical properties (tensile) Vs Number of layers for printed ABS layer thickness (4 layers $=0.8 \mathrm{~mm}$, 5 layers $=0.6 \mathrm{~mm}, 8$ layers $=0.4 \mathrm{~mm}, 15$ layers $=0.2 \mathrm{~mm}$ layer thickness)

The plot shows evidence of a linear correlation between deposited number of layers and

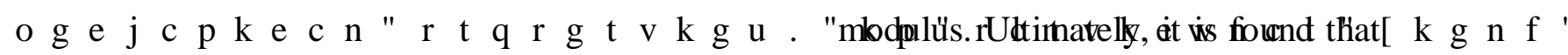
increasing the number of layers, increases the test samples mechanical properties. A bulk material strength limit or natural ideal threshold would limit the materials maximum strength.

When manufacturing using AM, ideal strength is assumed when the combined interlayer bond strength across the sum of the deposited layers equals the tensile strength of 
the bulk material, i.e. when $x \tau_{\text {interlayer }}=\sigma_{\text {bulk }}$. Yielding or failure may therefore initiate in either the bulk region or by delamination between layers. In this case, the weakest part would be deemed the bulk layer. Should the number of build layers influence a parts mechanical properties, it would imply the specific geometry, in addition to the build orientation, of a

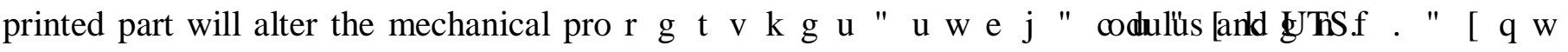
Current tensile and compression test methods such as ASTM and ISO standards do not consider test specimen shape or varying cross-sectional area as being influential on test results as material properties are fundamentally accepted as being independent of geometry, in particular, cross-sectional area. Torrado et. al, [30] conducted a tensile study on printed ABS material using 3 different ASTM specimen types, type I, IV and V. Test specimen types comprised of different width and gauge length while maintaining fixed thickness. Using fixed printing parameters, their study reported UTS to differ between the three different types, with results ranging between 34.5 to $39.9 \mathrm{MPa}$. Smith \& Dean in an earlier study [31] ran similar tests on ASTM specimen types I, II and III for polycarbonate samples, reporting a higher UTS variation of 26.1 to $41.6 \mathrm{MPa}$. The differing results in tensile properties obtained with the different specimen types, further advocates the need to standardise current mechanical testing methods for 3D printed material, while highlighting the lack of current understanding in strength mechanics associated with materials built using a fibre fusing and layer by layer deposition build process. As AM can also be achieved by a range of different material deposition processes, from droplet fusion approach using Polyjetting or complete layer polymerisation approach using digital light processing, each material processing format may have to be evaluated and appropriate standards defined.

\subsubsection{Influence of build layers on mechanical strength}

To test our assumptions regarding the influence of layer thickness on mechanical properties an experiment was conducted to test whether varying the number of build layers in a tensile specimen could directly change its mechanical strength, independent of layer thickness selection. Tensile tests were performed on modified type IV ASTM samples with an enlarged nominal thickness while keeping the individual layer thickness fixed, thereby increasing the 21 
total number of horizontal build layers at the gauge cross section A set of tensile samples were printed at $0.2 \mathrm{~mm}$ and $0.8 \mathrm{~mm}$ layer thickness, and comprised of a 3,6 and $9 \mathrm{~mm}$ nominal thickness, as seen in figure 8a). Testing parameters were maintained consistent with ASTM E8 and tests were conducted under identical parameters described in section 2.0. Figure 8b) illustrates a $9 \mathrm{~mm}$ thick sample, with a layer thickness of $8 \mathrm{~mm}$ pre and post testing on the universal test rig.

Figure 8c) illustrates the outcomes from tensile testing of the samples, where an acceptable variance in $0.2 \mathrm{~mm}$ layer samples was observed. This results highlights that there is no significant change in tensile properties for increased layer number at a build layer thickness of $0.2 \mathrm{~mm}$. By contrast, the loading capacity for the $0.8 \mathrm{~mm}$ set between nominal and $3 \mathrm{x}$ thickness is far more pronounced. This result highlights that there is a clear variation in the tensile properties for increased layer thickness at a build layer thickness of $0.8 \mathrm{~mm}$. Table 7 highlights changes to mechanical properties between the two sample sets. Both examined layer thicknesses demonstrate an increase in the UTS for increase layer number. The most significant result was the $\triangle U T S=7.3 \mathrm{MPa}$ for the $0.8 \mathrm{~mm}$ set, which contrasts sharply to a $\triangle U T S=$ $0.7 \mathrm{MPa}$ for the $0.2 \mathrm{~mm}$ set. The results show that changes in the number of build layers present within a printed solid material can alter elastic and plastic tensile properties, which becomes more pronounced as the layer thickness increases. We believe this is due to combined adhesion bond strength between the interlayers. The increase in Yield strength and UTS displayed by nominal and $3 \mathrm{x}$ thickness samples for the $0.8 \mathrm{~mm}$ set, despite comprising a greater number of layers, indicates a threshold limit does exist by which present number of interlayers may influence the total loading capacity of deposited printed material. If revised testing standards were implemented, these could look at observing mechanical loading capacity for a specified range of present layers or alternatively reporting on a deposited materials maximum potential loading capacity. It is noted that the present study has only examined one print orientation as opposed to a full treatment across all build orientations. When considered in the context of sample testing standardisation, the known anisotropic behaviour of FFF manufactured samples would likely complicates efforts to derive a suitable universal test protocol. 

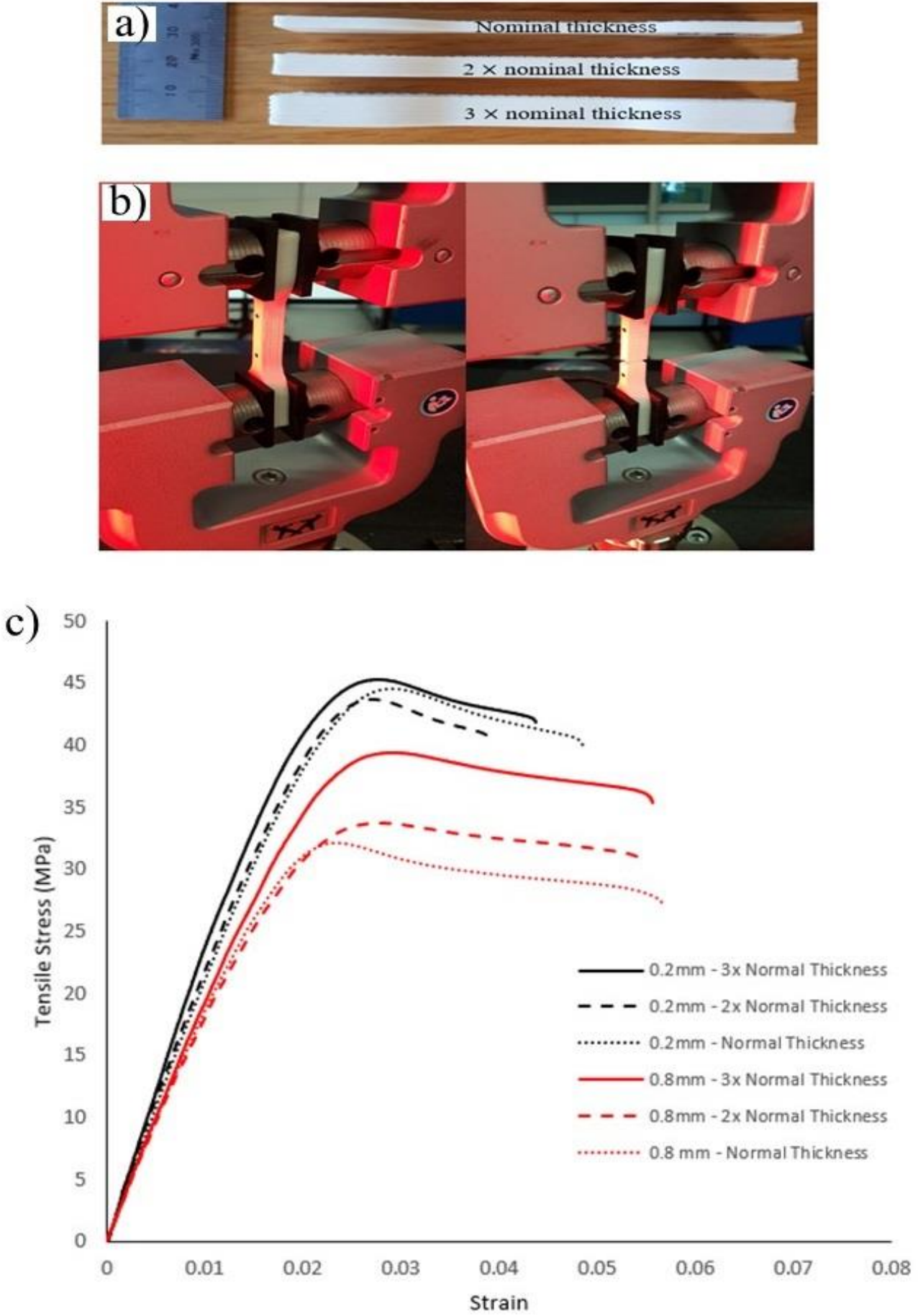

Figure 8: a) Modified ASTM Type IV set specimens printed at 0.8mm layer thickness. b) the 3x nominal thickness sample pre and post tensile testing. c) Tensile stress-strain curves using standard and modified ASTM type IV samples. 


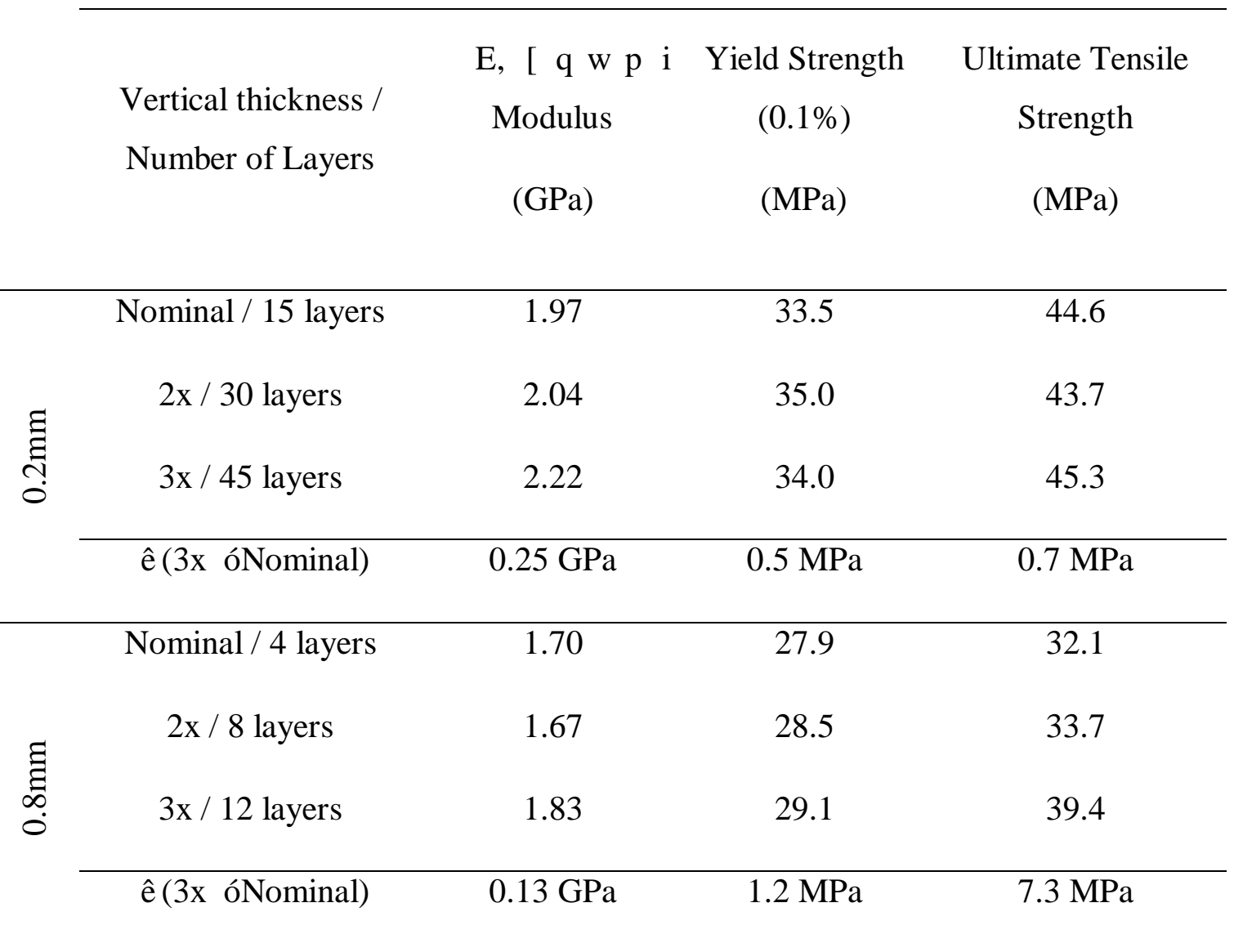

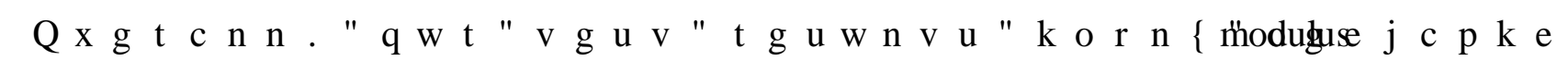
and UTS can become build geometry dependant for printed materials, based on the build layer thickness and the total number of build layers. The implication of this in practical applications are that printed components designed for functional loading could potentially be over or underrated in strength design and in worse case scenarios, could potentially result in part failure.

\subsection{Extrusion during pre-deposition causing material hardening}

The molecular orientation of ABS can be altered by shear flow during extrusion [32], resulting to unidirectional increase in mechanical strength and hardness. In our present study, 
during material deposition a $2.85 \mathrm{~mm}$ stock ABS filament is extruded through a $1 \mathrm{~mm}$ nozzle under the influence of high temperature and pressure. Material extruded through smaller nozzle sizes require greater pressure and subsequent exerted plastic strain. According to the literature, polymers including $\mathrm{ABS}$, can increase hardness under exposure to increased temperature, pressure or strain. It is possible these three mechanisms could be contributing to change in ABS properties based on the degree of exposure during extrusion. Equally, studies have found that lower extrusion temperatures and material flow rates can increase the proportion of molecular orientation [32]. We shall now examine such factors in the context of the understanding the discovered changes in mechanical properties.

\subsubsection{Polymer thermal degradation}

Temperature can trigger thermo-oxidative degradation in polymers like ABS, leading

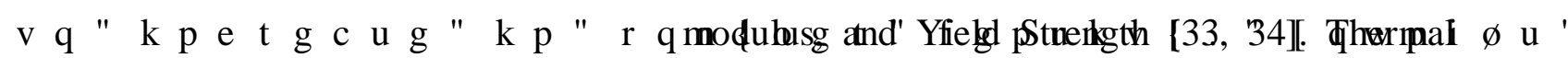
degradation occurs in $\mathrm{ABS}$ as heat energy causes poly-butadiene (PB) particles on surface layer to react with hydrogen under air exposure, producing heavier hydroperoxide radicals such as carbonyl and hydroxyl products. Tiganis et, al. [34] found an increase in ABS mechanical properties as result of identified carbonyl and hydroxyl products produced on the surface due to thermal aging process at $>80^{\circ} \mathrm{C}$. Mechanical properties including hardness, impact strength,

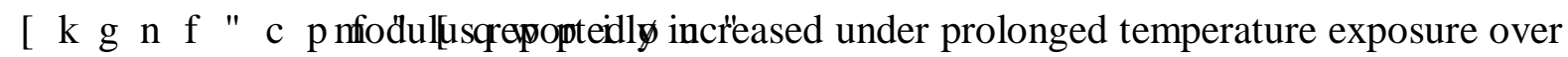
a 168 hour period [34]. Although most studies commonly assess polymer thermal degradation with repeated process cycling or thermal aging processes for material processing/recycling advancement, an extrusion-based study by Camacho \& Karlsson [35] found substantial thermal degradation can occur in blended polymers during their first or second extrusion cycle.

In the present study, thermal degradation in $\mathrm{ABS}$ would be possible under FFF extrusion environment. In recent studies by Mohammed et al. [36, 37], it was found that repeated thermal extrusion of ABS plastic using FFF resulted in a reduction in the Yield strength for increased number of thermal reforming cycles. Taking this into consideration under the material pre-deposition process, it is possible that a reasonable degree of thermal 
degradation may occur during the extrusion and layering process. In addition, printing polymers at smaller layer thickness could cause greater thermal degradation, as more PB particle surface layer is exposed leading to increased carbonyl and hydroxyl product formation.

\subsubsection{Extrusion strain hardening}

A well-known strain-hardening mechanism associated with semi-crystalline polymers is strain-induced crystallisation, such as in the stretch-blow moulding of PET [38, 39]. Similar outcomes of strain based molecular ordering mechanisms are possible in amorphous polymers such as PLA, and amorphous states of PET. Strain hardening can also occur in polybutadiene rubber (BR), a constituent of $\mathrm{ABS}$ [40], leading us to believe this mechanism to be relevant to the manufactured ABS samples in this study. The induced ordering event occurs as applied loading triggers non-oriented amorphous phases or chains to interact, causing molecular alignment parallel to the direction of applied loading. Gorlier [39] perceived this interaction as cross-link nucleation between chains and phases rather than perfect and large crystalline formation following a study on amorphous PET. However, few studies have reported on direct strain-hardening behaviour of ABS [41-44]. In observing sheet thermoforming of ABS, Kyun et. al, found strain-hardening evident under wide range of temperatures $140^{\circ} \mathrm{C} \pm 200^{\circ} \mathrm{C}$. These temperatures are similar to extrusion environment of FFF 3D printing. A study by Tatsuhiro (Takahashi, Wu et al. 1997) reported the concentration and state of butadiene particles in ABS had an influence on the polymers ability to strain-harden or soften. It is evident, more experimental based studies are required in this area to identify molecular particle interaction which is promoting increasing material hardness and related mechanical properties.

We therefore aim to explain the strain hardening mechanism as a contributory mechanism for the changes in mechanical properties observed in the present study. When virgin material is extruded through a printing nozzle, the material cross-section undergoes dramatic reduction, depicted in Fig. 9a). Induced stress and temperature are necessary for this reduction, while additional stresses are introduced during thermal relaxation where minor 
material shrinkage occurs. In effect, the resultant plastic strain may alter the material molecular structure, increasing hardness and strength.
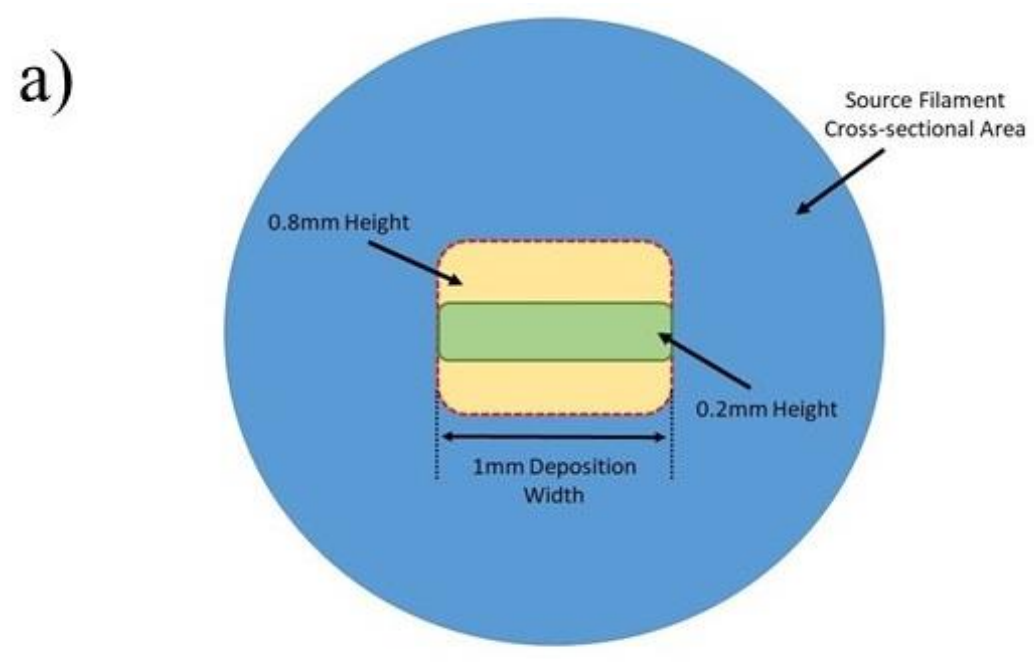

$$
\% R A=\frac{A_{\text {Deposition }}-A_{o}}{A_{0}}
$$

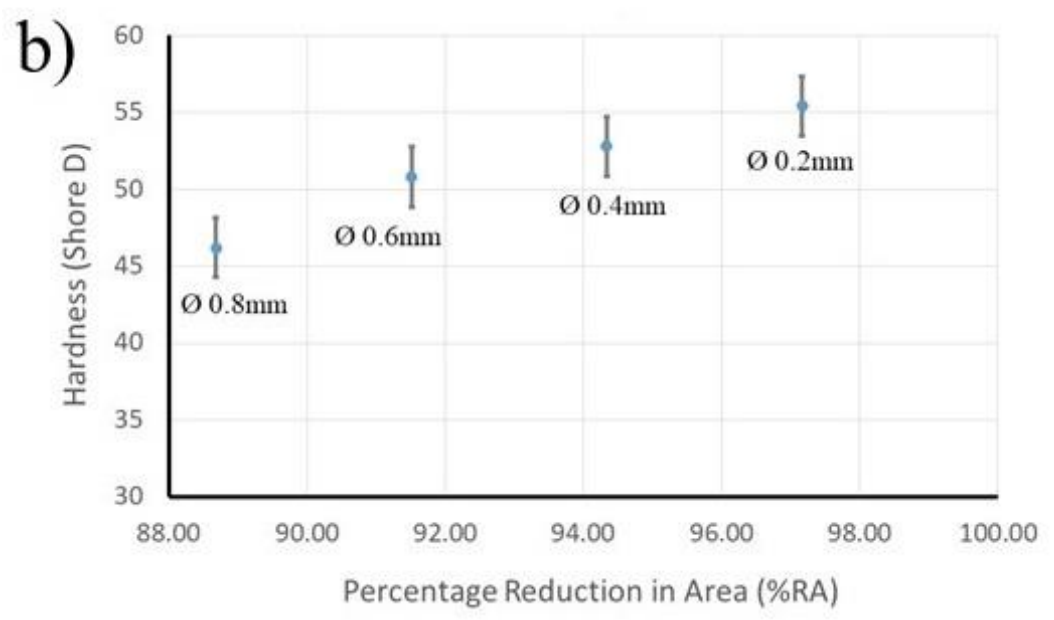

Figure 9: a) Scaled display of material cross-sectional area reduction. b) Measured hardness on nontested ABS Tensile samples (0.2mm-0.8mm layer thickness) Vs Percentage Area Reduction (\%RA)

Hardness tests were conducted on non-tested ABS tensile samples using a digital durometer, (Enpaix EHS5D, Polygon Instrument LTD, China). Samples were measured 27 
immediately post printing according to previously detailed parameters in Table 2.0. Tests were conducted according to ASTM D2240, using 5kg applied loading. An average hardness was taken from 50 measurements on each sample and plotted results of the hardness measurements can be seen in Fig. 9b). Results shows an increasing trend in material hardness with increased \%RA, showing evidence that samples printed at smaller layer thickness, exhibit increased strain-hardening due to having undertaken larger area-reduction through extrusion.

The calculated percentage area of reduction $(\% R A)$ can provide a measure of the amount of induced strain on the extruded material. Based on the fixed $1 \mathrm{~mm}$ nozzle size used in this study, $\% R A$ figures for material printed at layer thickness from $0.2 \mathrm{~mm} \pm 0.8 \mathrm{~mm}$ ranged between $97.2 \%-88.7 \% R A$. These relatively high percentages highlight that the extruded material is subjected to a significant amount of induced strain prior to material deposition. The smaller the volume of deposited material, i.e. a lower printed layer thickness, the higher degree of induced strain resulting in an increased sample hardness.

\subsection{Summary}

The mechanical tensile and compression testing of ABS samples, produced by FFF at different layer thickness ranging from $0.2 \mathrm{~mm}$ to $0.8 \mathrm{~mm}$, found the selection of layer thickness to have a significant impact on mechanical strength and properties. This included measured differences in the < R X Qnfo\&uks, Yield strength, UTS, compression yield and compression modulus. Standard tensile and compression tests to ASTM standards revealed samples printed at the smallest examined layer thickness of $0.2 \mathrm{~mm}$ attained the highest strength properties. Conversely, the largest examined layer thickness of $0.8 \mathrm{~mm}$ measured the lowest strength properties. The degradation of strength in printed samples was found to correlate with increasing layer thickness in sequential order, while material properties tend towards ideal strength with decreasing layer thickness.

Three sample properties, comprising the sample porosity, number of deposited layer for a fixed geometry and deposition volume dependant stress hardening were examined to determine the underlying layer thickness interactions on material strength. The combinatory effect of 
these mechanisms are believed to attribute the overall strength degradation observed with FFF material when printed at larger layer thickness. In the present study, we have fixed several parameters with respect to material deposition, utilising two shells and the raster deposition direction, which alternated between $45^{\circ}$ and $135^{\circ}$ for each respective layer. The work by Torrado et al [30] and Smith \& Dean [31] clearly highlights the variability of mechanical strength with respect to raster deposition angle, which also appears to be independent of build polymer. It is equally likely that factors such as variation in the shell number and print orientation will also result in changes in mechanical properties for parts with varying layer thickness, and are parameters the authors will investigate in future studies.

With respect to sample porosity, 3D cross-sectional profilometry of the printed material found the measured porosity to be greater when printing with larger layer thickness. Measured porosity made up $2.72 \%$ of total cross-section area in material printed at $0.8 \mathrm{~mm}$ layer thickness, while by contrast a porosity of $0.14 \%$ was measured in material printed at $0.2 \mathrm{~mm}$ layer thickness. For smaller layer thicknesses the measured porosity data correlates with physical mass and volume measurements taken of samples. However, for larger layer thicknesses which saw a twenty-fold increase in relative porosity compared to $0.2 \mathrm{~mm}$ layer thicknesses, the measured porosity was found greatly insufficient to entirely contribute to the measured loss in material strength. Feasibly, the measured porosity residing in the printed material could act as stress concentration points for crack initiation and layer delamination sources, which could attribute for the measured loss in mechanical strength and stiffness. Future work analysing how porosity may be detrimental to FFF printed material could offer further insight on the matter.

The number of deposited layers was found to influence a printed samples loading capacity and mechanical strength properties such as Yield, elastic modulus (tensile and compression) and UTS. It was found that for increased number of layers present in a fixed volume, there was an overall increase in sample strength. We believe this is a result of the combined adhesion bonding strength resulting from increased instances of thermally driven polymer chain entanglement from the increased number of deposition interfaces. This also implies that the effect is dependent on the residual heat found between the previously printed layer and the newly deposited material. Given that as the layer thickness decreases the mass of deposited 
material decreases, the heat imparted during subsequent layer deposition may be sufficient to allow for thermally driven polymer entanglement to reach further into each layer. This is somewhat analogous to build improvements in metal SLM AM when considering the layer thermal history [5].

We believe thermal and strain hardening events are possible during material extrusion when printing using FFF. High temperature, pressure and induced strain under extrusion can alter the molecular structure in ABS causing an increase in material hardness and strength. Hardness measurements on ABS printed tensile samples found smaller layer thickness samples to be harder compared with larger layer thickness samples, with an overall observed linear correlation. High extrusion temperatures can also feasibly trigger thermo-oxidative degradation to occur in ABS. In such instances poly-butadiene (PB) particles to react with hydrogen, forming heavy carbonyl and hydroxyl products on exposed surface, leading to increased material hardness and strength. Samples printed at smaller layer thickness could lead to increased degradation due to greater surface exposure resulting from smaller deposition layers. Future work on phase microstructural analysis in the cross-section of bulk printed material would validate thermo degradation growth with printed material layer thickness range.

Differences in tensile properties between $0.2 \mathrm{~mm}$ and $0.8 \mathrm{~mm}$ layer thickness comprise $\Delta E=23 \%, \Delta Y$ ield $=27 \%, \Delta U T S=19 \%$, and compression properties comprise $\Delta Y$ Yield $=$ $37 \%, \Delta E=19 \%$. Current tensile and compression standards for rigid plastics such as ASTM and equivalent ISO, do not address variation in mechanical properties of plastics processed by FFF. Moreover, these mechanical properties of printed samples may become geometry and build parameter dependant. Experimental tensile results on increasing cross-section tensile samples uncovered these properties, where loading behaviour was found to vary due to number of build layers present affecting the interlayer bond strength. This large range of measured mechanical properties influenced by selection of layer thickness and geometry strongly supports the need for current mechanical testing standards such as ASTM and ISO to incorporate separate standardisation of FFF printed material. Beyond FFF, studies should be performed to establish if alternative AM technologies, with differing material deposition techniques may also see similar variances in mechanical strength. Development of guidelines 
on sample preparation method for printed material in mechanical testing standards will aid in the regulation of reported mechanical properties and enable improved mechanical reliability of printed materials in functional design applications. We also conclude that a degree of caution should also be taken when FFF printing parts with intended mechanical characteristics, particularly at larger layer thicknesses, as our results suggest mechanical integrity may be compromised compared to expectation found from testing at smaller layer thicknesses. Such findings may have implication for larger layer thickness printing technologies such as the BAAM printers, and when using a larger layer thickness to reduce the overall printing time of a given part. Ultimately, more studies are also required to explore the individual facets which have been found influential on the mechanical integrity of a respective part, particularly if FFF is to be considered an industrial manufacturing paradigm.

\section{References}

1. Bandyopadhyay, A., S. Vahabzadeh, A. Shivaram, and S. Bose, Three-dimensional printing of biomaterials and soft materials. MRS Bulletin, 2015. 40(12): p. 1162-1169.

2. Costa, P.F., C. Vaquette, Q. Zhang, R.L. Reis, S. Ivanovski, and D.W. Hutmacher, Advanced tissue engineering scaffold design for regeneration of the complex hierarchical periodontal structure. Journal of clinical periodontology, 2014. 41(3): p. 283-294.

3. Mohammed, M.I., P.S. Badwal, and I. Gibson, Design and fabrication considerations for three dimensional scaffold structures. KnE Engineering, 2017. 2(2): p. 120-126.

4. Mohammed, M.I. and I. Gibson, Design of Three-Dimensional, Triply Periodic Unit Cell Scaffold Structures for Additive Manufacturing. Journal of Mechanical Design, 2018. 140(7): p. 071701-071701-10.

5. Khorasani, A.M., I. Gibson, A. Ghaderi, and M.I. Mohammed, Investigation on the effect of heat treatment and process parameters on the tensile behaviour of SLM Ti6Al-4V parts. The International Journal of Advanced Manufacturing Technology, 2018.

6. Huang, S.H., P. Liu, A. Mokasdar, and L. Hou, Additive manufacturing and its societal impact: a literature review. The International Journal of Advanced Manufacturing Technology, 2013. 67(5): p. 1191-1203.

7. Crump, S.S., Apparatus and method for creating three-dimensional objects 1989, Stratasys Inc.

8. Jones, R., P. Haufe, E. Sells, P. Iravani, V. Olliver, C. Palmer, and A. Bowyer, RepRap the replicating rapid prototyper. Robotica, 2011. 29(1): p. 177-191. 
9. Mohammed, M.I., M. Mohan, A. Das, M.D. Johnson, P.S. Badwal, D. McLean, and I. Gibson, A low carbon footprint approach to the reconstitution of plastics into 3Dprinter filament for enhanced waste reduction. KnE Engineering, 2017. 2(2): p. 234241.

10. Le Duigou, A., M. Castro, R. Bevan, and N. Martin, 3D printing of wood fibre biocomposites: From mechanical to actuation functionality. Materials \& Design, 2016. 96: p. 106-114.

11. Wang, X., M. Jiang, Z. Zhou, J. Gou, and D. Hui, 3D printing of polymer matrix composites: A review and prospective. Composites Part B: Engineering, 2017. 110: p. 442-458.

12. Tekinalp, H.L., V. Kunc, G.M. Velez-Garcia, C.E. Duty, L.J. Love, A.K. Naskar, C.A. Blue, and S. Ozcan, Highly oriented carbon fiber-polymer composites via additive manufacturing. Composites Science and Technology, 2014. 105: p. 144-150.

13. Mohammed, M.I., M.G. Ridgway, and I. Gibson. Development of virtual surgical planning models and a patient specific surgical resection guide for treatment of a distal radius osteosarcoma using medical $3 D$ modelling and additive manufacturing processes. in Proceedings of the 28th Solid Freeform Fabrication Symposium, Austin, TX. 2017.

14. Mitsouras, D., P. Liacouras, A. Imanzadeh, A.A. Giannopoulos, T. Cai, K.K. Kumamaru, E. George, N. Wake, E.J. Caterson, and B. Pomahac, Medical 3D printing for the radiologist. Radiographics, 2015. 35(7): p. 1965-1988.

15. Mohammed, M.I., D. Wilson, E. Gomez-Kervin, C. Vidler, L. Rosson, and J. Long, The recycling of E-Waste ABS plastics by melt extrusion and $3 D$ printing using solar powered devices as a transformative tool for humanitarian aid.

16. Turner, B.N. and S.A. Gold, A review of melt extrusion additive manufacturing processes: II. Materials, dimensional accuracy, and surface roughness. Rapid Prototyping Journal, 2015. 21(3): p. 250-261.

17. Grémare, A., V. Guduric, R. Bareille, V. Heroguez, S. Latour, N. L'heureux, J.C. Fricain, S. Catros, and D. Le Nihouannen, Characterization of printed PLA scaffolds for bone tissue engineering. Journal of Biomedical Materials Research Part A, 2017.

18. Curran, S., P. Chambon, R. Lind, L. Love, R. Wagner, S. Whitted, D. Smith, B. Post, R. Graves, and C. Blue, Big area additive manufacturing and hardware-in-the-loop for rapid vehicle powertrain prototyping: A case study on the development of a 3-Dprinted Shelby Cobra. 2016, SAE Technical Paper.

19. Sood, A.K., R.K. Ohdar, and S.S. Mahapatra, Parametric appraisal of mechanical property of fused deposition modelling processed parts. Materials \& Design, 2010. 31(1): p. 287-295.

20. Sood, A.K., R.K. Ohdar, and S.S. Mahapatra, Experimental investigation and empirical modelling of FDM process for compressive strength improvement. Journal of Advanced Research, 2012. 3(1): p. 81-90. 
21. Lužanin, O., D. Movrin, and M. Plančak, Effect of layer thickness, deposition angle, and infill on maximum flexural force in FDM-built specimens. Journal for Technology of Plasticity, 2014. 39(1): p. 49-58.

22. Che, C.W., L. Ta-Wei, and H. Shr-Shiung, Optimizing the rapid prototyping process by integrating the Taguchi method with the Gray relational analysis. Rapid Prototyping Journal, 2007. 13(5): p. 304-315.

23. Tymrak, B.M., M. Kreiger, and J.M. Pearce, Mechanical properties of components fabricated with open-source 3-D printers under realistic environmental conditions. Materials \& Design, 2014. 58: p. 242-246.

24. Wu, W., P. Geng, G. Li, D. Zhao, H. Zhang, and J. Zhao, Influence of Layer Thickness and Raster Angle on the Mechanical Properties of 3D-Printed PEEK and a Comparative Mechanical Study between PEEK and ABS. Materials, 2015. 8(9): p. 5271.

25. Mohamed, O.A., S.H. Masood, and J.L. Bhowmik, Experimental investigations of process parameters influence on rheological behavior and dynamic mechanical properties of FDM manufactured parts. Materials and Manufacturing Processes, 2016. 31(15): p. 1983-1994.

26. Standard Test Method for Tensile Properties of Plastics.

27. Standard Test Method for Compressive Properties of Rigid Plastics.

28. Gordeev, E.G., A.S. Galushko, and V.P. Ananikov, Improvement of quality of 3D printed objects by elimination of microscopic structural defects in fused deposition modeling. PloS one, 2018. 13(6): p. e0198370.

29. Lee, B.H., J. Abdullah, and Z.A. Khan, Optimization of rapid prototyping parameters for production of flexible ABS object. Journal of Materials Processing Technology, 2005. 169(1): p. 54-61.

30. Torrado, A.R. and D.A. Roberson, Failure analysis and anisotropy evaluation of 3Dprinted tensile test specimens of different geometries and print raster patterns. Journal of Failure Analysis and Prevention, 2016. 16(1): p. 154-164.

31. Smith, W.C. and R.W. Dean, Structural characteristics of fused deposition modeling polycarbonate material. Polymer testing, 2013. 32(8): p. 1306-1312.

32. Rodríguez, J.F., J.P. Thomas, and J.E. Renaud, Mechanical behavior of acrylonitrile butadiene styrene (ABS) fused deposition materials. Experimental investigation. Rapid Prototyping Journal, 2001. 7(3): p. 148-158.

33. Boldizar, A. and K. Möller, Degradation of ABS during repeated processing and accelerated ageing. Polymer Degradation and stability, 2003. 81(2): p. 359-366.

34. Tiganis, B., L. Burn, P. Davis, and A. Hill, Thermal degradation of acrylonitrilebutadiene-styrene (ABS) blends. Polymer degradation and stability, 2002. 76(3): p. 425-434.

35. Camacho, W. and S. Karlsson, Assessment of thermal and thermo-oxidative stability of multi-extruded recycled PP, HDPE and a blend thereof. Polymer Degradation and Stability, 2002. 78(2): p. 385-391.

36. Mohammed, M.I., A. Das, E. Gomez-Kervin, D. Wilson, and I. Gibson. EcoPrinting: Investigating the use of $100 \%$ recycled Acrylonitrile Butadiene Styrene (ABS) for 
Additive Manufacturing. Proceedings of the 28th Annual International Solid Freeform Fabrication Symposium, 2017, 532-542.

37. Mohammed, M.I., D. Wilson, E. Gomez-Kervin, B. Tang, and J. Wang, Investigation of Closed-Loop Manufacturing with Acrylonitrile Butadiene Styrene over Multiple Generations Using Additive Manufacturing. ACS Sustainable Chemistry \& Engineering, 2019, 7, 16, 13955-13969, doi.org/10.1021/acssuschemeng.9b02368.

38. Stoclet, G., R. Seguela, J. Lefebvre, S. Elkoun, and C. Vanmansart, Strain-induced molecular ordering in polylactide upon uniaxial stretching. Macromolecules, 2010. 43(3): p. 1488-1498.

39. Gorlier, E., J.-M. Haudin, and N. Billon, Strain-induced crystallisation in bulk amorphous PET under uni-axial loading. Polymer, 2001. 42(23): p. 9541-9549.

40. Toki, S., I. Sics, B.S. Hsiao, M. Tosaka, S. Poompradub, Y. Ikeda, and S. Kohjiya, Probing the nature of strain-induced crystallization in polyisoprene rubber by combined thermomechanical and in situ X-ray diffraction techniques. Macromolecules, 2005. 38(16): p. 7064-7073.

41. Kyun, L.J., V.T. L., and S.C. E., Influence of initial sheet temperature on $A B S$ thermoforming. Polymer Engineering \& Science, 2001. 41(10): p. 1830-1844.

42. Li, L., T. Masuda, and M. Takahashi, Elongational flow behavior of ABS polymer melts. Journal of Rheology, 1990. 34(1): p. 103-116.

43. Saito, Y., Extensional properties of ABS. II. Dynamic viscoelastic and extensional properties of ABS. Nihon Reoroji Gakkaishi, 1982. 10: p. 128-134.

44. Takahashi, T., W. Wu, H. Toda, J.-i. Takimoto, T. Akatsuka, and K. Koyama, Elongational viscosity of $A B S$ polymer melts with soft or hard butadiene particles. Journal of NonNewtonian Fluid Mechanics, 1997. 68(2): p. 259-269. 